(C) <2016>. This accepted manuscript is made available under the CC-BY-NC-ND 4.0 license http://creativecommons.org/licenses/by-nc-nd/4.0/.

The final published manuscript is available as: S. Zen, G. Zolezzi, M. Toffolon, A.M. Gurnell. 2016. Biomorphodynamic modelling of inner bank advance in migrating river bends. Advances in Water Resources 93 Part B, 166-181, http://dx.doi.org/10.1016/j.advwatres.2015.11.017

\title{
Biomorphodynamic modelling of inner bank advance in migrating meander bends
}

\author{
Simone Zen ${ }^{1}$, Guido Zolezzi ${ }^{1}$, Marco Toffolon ${ }^{1}$, Angela M. Gurnell ${ }^{2}$ \\ ${ }^{1}$ Department of Civil, Environmental and Mechanical Engineering, University of Trento, Trento, \\ Italy. \\ ${ }^{2}$ School of Geography, Queen Mary, University of London, London, United Kingdom.
}

\begin{abstract}
We propose a bio-morphodynamic model at bend cross-sectional scale for the lateral migration of river meander bends, where the two banks can migrate separately as a result of the mutual interaction between river flow, sediments and riparian vegetation, particularly at the interface between the permanently wet channel and the advancing floodplain. The model combines a nonlinear analytical model for the morphodynamic evolution of the channel bed, a quasi-1D model to account for flow unsteadiness, and an ecological model describing riparian vegetation dynamics. Simplified closures are included to estimate the feedbacks among vegetation, hydrodynamics and sediment transport, which affect the morphology of the river-floodplain system. Model tests reveal the fundamental role of riparian plants in generating bio-morphological patterns at the advancing floodplain margin. Importantly, they provide insight into the biophysical controls of the 'bar push' mechanism and into its role in the lateral migration of meander bends and in the temporal variations of the active channel width.
\end{abstract}

Keywords: meander bio-morphodynamics, non-linear model, riparian vegetation, bar push, ridgesswales pattern, width variation. 


\section{Introduction}

It has long been recognised that meander bends migrate laterally as a result of a curvature-forced flow pattern that causes erosion of the outer, concave bank and deposition of sediment at the inner, convex bank (Leopold and Wolman, 1960; Seminara, 2006). Most river meandering modelling has been based on the solution of the physical laws for momentum and mass conservation for water flow over a movable bed (e.g. Ikeda et al., 1981; Johannesson and Parker, 1989; Zolezzi and Seminara, 2001; Bolla et al., 2009; Luchi et al., 2011). However, in addition to flow and sediment dynamics, the contribution of vegetation to channel morphodynamics is becoming increasingly recognised (e.g. Corenblit et al., 2007, 2009a). In this context, certain key plant species act as physical 'ecosystem engineers', interacting with flow and sediment processes to drive channel morphological changes (Gurnell et al., 2012; Gurnell, 2014), and in some cases to induce a topographic signature of vegetation on river channel form (Bertoldi et al., 2011b). In the case of meandering rivers, the progressive deposition of sediment, in the form of a point bar, at the convex bank is often associated with the development of a corrugated floodplain surface, characterized by a succession of ridges and swales. These ridge-swale forms represent a succession of features, which originated as meander scrolls or scroll bars (e.g. Figure 1) deposited in association with point bar development and then progressively incorporated into the floodplain as the meander migrates (Hickin, 1974; Hickin and Nanson, 1975; Nanson, 1980; Nanson and Croke, 1992). Field observations have revealed that scroll bars are often cored and stabilised by woody and other vegetative material (e.g. Nanson, 1981). In some cases this vegetative material sprouts to form a riparian shrub cover that further enhances local sediment retention and ridge / scroll development (Page and Nanson, 1982; McKenney, et al., 1995; Gurnell and Petts, 2006).

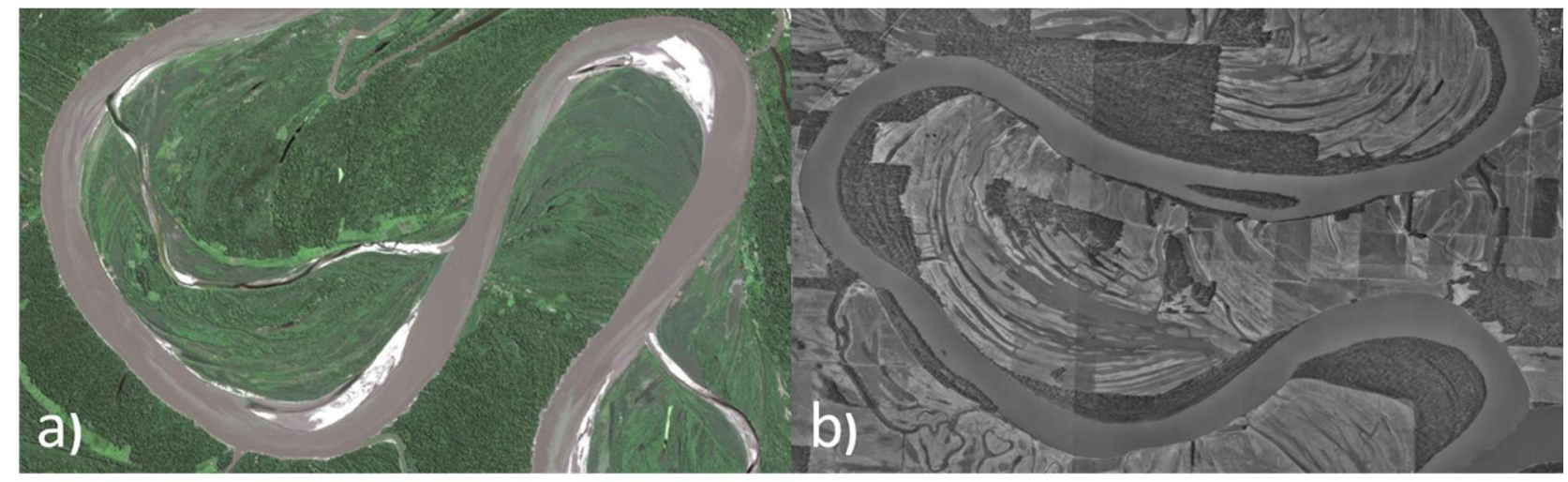

Figure 1 Example of scroll formations at the inner bank of evolving meanders within vegetated floodplains, suggesting the contemporary presence of patterns in vegetation distribution and in the floodplain topography. a) Rio Ucayali, Peru and b) Wabash River, close to the Kentucky border, USA from an historical image - source Google Earth.

These mutual feedbacks among flow, sediment and riparian vegetation dynamics in evolving meander bends can be viewed as a series of interacting 'unit processes' that control bank dynamics, sediment retention and the initiation of characteristic vegetated pioneer landforms. The reinforcing action of roots stabilizes bank sediments increasing bank resistance to erosion processes, thus affecting the migration rates of the inner and outer banks of meander bends and inducing morphological changes at both local (cross-section) and reach scales (Allmendinger et al., 2005; Braudrick et al., 2009). Over-bank deposition is particularly relevant in the aggradation processes of meander inner banks (Hickin, 1974) and decreases with distance from the river edge, partly because, 
in vegetated floodplains, the drag resistance of mature trees is lower than that of early-stage bushy growth forms (McKenney et al., 1995).

Such complex dynamics are fundamentally related to the natural variability of river flows, both because of the direct action of flow on channel morphodynamics and also because of indirect impacts on riparian vegetation evolution. In particular, very high flows determine channel widening through net bank erosion, while an absence of very high flows allows width contraction through vegetation growth and aggradation of scrolls at the convex bank. At a decadal scale, the imbalance between the rate of cutbank erosion and point-bar accretion has been observed to lead to a concertina-like movement of the channel with the cutbank retreating and then pausing, and the convex bank advancing to 'catch up' (Nanson, 1981; Nanson and Hickin, 1983). This discontinuous process has been linked with fluvial processes at the scale of the overall river planform (e.g. Hooke, $2007 ; 2008)$ but has been represented as a continuous process in classical meander morphodynamic models, which implicitly assume that the two opposite banks move at the same rate so that the channel width is constant in time (Howard, 1992; Sun et al., 1996; Camporeale et al., 2005; Crosato, 2007; Frascati and Lanzoni, 2009).

The structure of riparian tree communities is also strongly influenced by the hydrological regime through the processes of flow disturbance and moisture supply to the vegetation. The temporal distribution of free surface elevation influences the delivery of seeds and vegetative propagules to recruitment sites, the moisture conditions and disturbance exposure at those sites, and thus potential recruitment success (e.g. Mahoney and Rood, 1998). Free surface variations also influence groundwater levels in the alluvial aquifer and thus the availability of moisture to support plant survival and growth (e.g. Perona et al., 2012; Gurnell, 2016). During floods, flow may reduce vegetation coverage by eroding, undermining or uprooting vegetated areas, particularly on the outer bank, and also by burying vegetation, particularly on the inner bank (Parker et al., 2011; Crouzy and Perona, 2012). During the subsequent low flow stages, buried vegetation may sprout through newly deposited sediments on the point bar and new plants may germinate from the newlydeposited sediment. Plants can also colonize the exposed sediments of the point bar at the inner bank following propagule dispersal by water during flow pulses or by other agents, particularly wind (Gurnell et al., 2008a,b). As a result, vegetation structure and distribution within the riparian corridor reflects the rate of river migration and proximity to the river edge, local topography and hydrological conditions (McKenney et al., 1995; Robertson and Augsburger, 1999; Robertson, 2006; Perucca et al., 2006, 2007). Furthermore, the presence of a hotspot of physical ecosystem engineering by plants occurs on the inner bank as the development of scroll bars and extension of the floodplain is strongly influenced by the rapid growth of particular disturbance-tolerant plant species (Gurnell and Petts, 2006; Gurnell, 2014).

Despite recent quantitative advances provided by flume experiments (Braudrick et al., 2009), the above processes and dynamics are quite well known from a conceptual and qualitative viewpoint, mainly related to field observations of particular river systems. However, with a few notable exceptions (e.g. Perucca et al., 2006, 2007), there has been little attempt to incorporate these vegetation-related processes into modelling approaches to simulate river meandering morphodynamics.

Modelling research in meander morphodynamics is traditionally based on a unified, timeaveraged parameterization of the markedly distinct processes occurring at the advancing and cutting banks (Ikeda et al., 1981, Luchi et al., 2011), even when accounting for the active role of riparian vegetation (Perrucca et al., 2006, 2007) or floodplain spatial heterogeneities (Guneralp and Rhoads, 2011). This knowledge gap has prevented the advancement of understanding of the key controls on floodplain pattern development, including the evolution of scroll bars and temporal adjustments in the channel width of evolving meander bends. Such issues have implications for 
broader questions concerning the conditions that may favour the systematic presence of chute cutoffs on some meandering rivers (Grenfell, et al., 2011), and the geomorphological transitions from single-thread to multi-thread meandering channels (Kleinhans and van den Bergh, 2011; Zolezzi et al., 2012).

Only recently have modelling efforts addressed the separate dynamics of each river bank, although with some bias towards the eroding bank, and floodplain-channel interactions. Following the novel approach of Parker et al. (2011), Eke et al. (2014) have modelled the planform evolution of river meanders by introducing separate closure relations for the migration of the advancing and the retreating banks. Together with recent experimental work (van Dijk, et al., 2013) they predict how channel width adjusts through time in response to a dynamic 'dialogue' between the two banks, raising the question of whether width adjustments and channel migration are mostly supported by a 'bar push' or a 'bank pull' process. These decoupled bank relations account for the sediment exchange between the two bank regions and the channel region, but they lack an explicit description of the underlying biophysical processes of flow-sediment-vegetation interactions.

In this paper, we develop a bio-morphodynamic model that is able to predict, albeit in a simplified way, the mutual interaction between flow, channel-floodplain morphodynamics and riparian vegetation dynamics in evolving meander bends. We also explore the model outcomes:

1) to gain a quantitative insight into the dynamics of inner bank advance and its potential 'bar push' role in lateral bend migration;

2) to detect possible hydrological and vegetation controls on the temporal adjustments of channel width and on the development of topographic and vegetation patterns in the accreting floodplain region at the inner bank.

The model couples a minimalist approach for the interaction between riparian vegetation and river processes with a non-linear analytical model for the morphodynamics of a meander bend. Our approach represents one of the first attempts to develop a biophysically-based model for the advance of the inner bank of meander bends.

\section{Methods}

In order to achieve the objectives listed above, the bio-morphodynamic model incorporates the lowest possible level of complexity and, in its first stage of development, the interactions between the ecological system and flow dynamics have been investigated at the cross-section scale.

\subsection{Modelling strategy and notations}

The proposed model reproduces a suite of biophysical 'unit' processes through an algorithm that links representative sub-models for each unit process. Before providing a detailed description of each of these sub-models, a broad overview of the adopted modelling strategy is presented. 


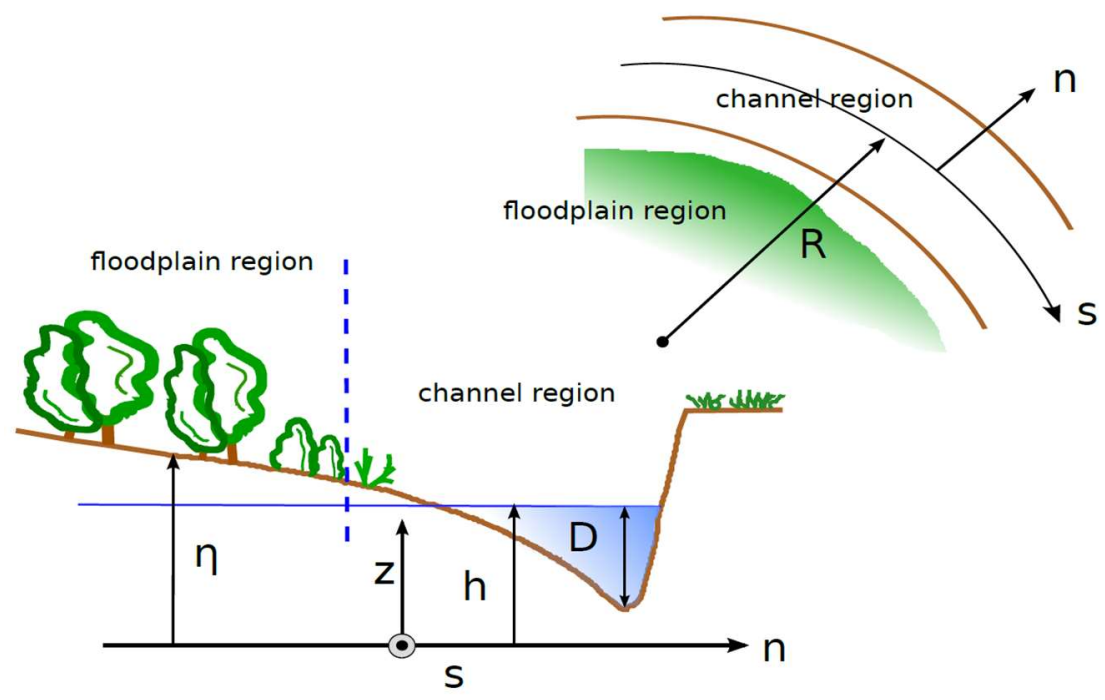

Figure 2 Schematic representation of the meandering channel and notations.

The modelling reference system is illustrated in Figure 2 where also the main geometric and hydraulic parameters are defined. The vegetation biomass is defined by the dimensionless parameter $b^{*}$, which represents the local biomass density and ranges from 0 to $1 ; h$ and $\eta$ denote the free water surface and the bed elevation, respectively; and $D$ represents the channel water depth related to the discharge $Q$ at each time $t$. The variables are referenced to a curvilinear reference system $(s ; n ; z)$, in which $s$ is the longitudinal (streamwise) coordinate, $n$ is the transversal coordinate (orthogonal to $s$ ) and $z$ is the vertical axis pointing upwards. Moreover, the partitioning of the cross-section into a 'floodplain region' and a 'channel region' depends on the local value of the Shields parameter $\vartheta^{*}$ compared to the limit value for sediment mobility $\vartheta_{c}^{*}$. The Shields parameter represents the dimensionless form of the shear stress acting on the bed and is defined as

$$
\vartheta^{*}=\frac{S D}{\Delta d_{50}}
$$

where $S$ is the longitudinal slope of the floodplain, $\Delta$ is the relative submerged sediment density ratio and $d_{50}$ represents the median grain size. Hereinafter the asterisk denotes dimensionless quantities. 


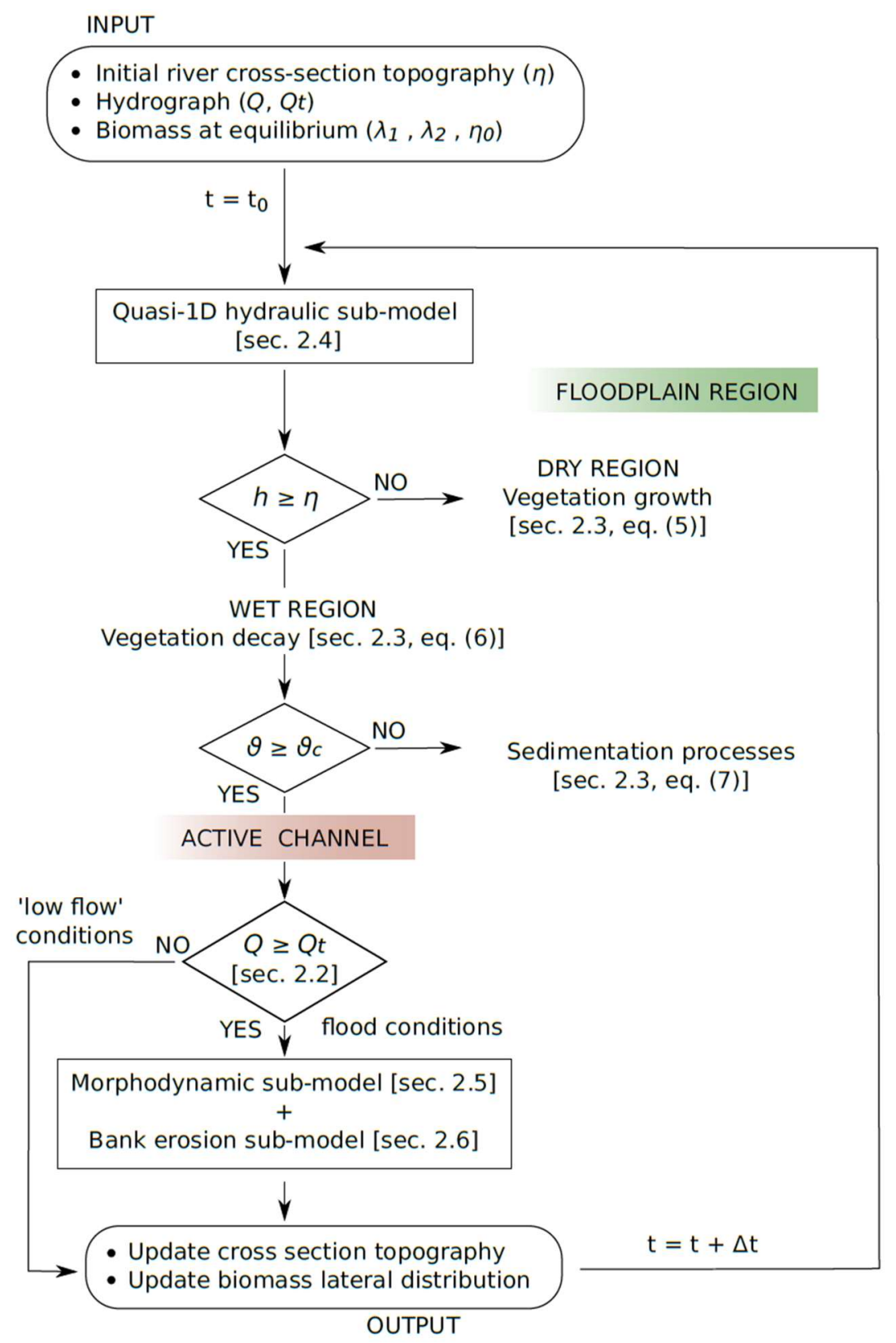

Figure 3 Flow chart of the bio-morphodynamic model. See text for notations.

Figure 2 provides a synthetic representation of the model algorithm. The different timescales of river morphodynamics and of riparian vegetation evolution are reflected in the choice of sub-models and of their interaction rules. The model partitions the river cross-section into two environments where different sub-models apply depending on flow stage (Figure 3): an active channel region, where morphodynamic processes occur, and a floodplain region, in which sedimentation progressively increases the ground surface elevation during over bank flows. The model requires an input hydrograph, whereby the temporal oscillations of water stage at low flows determine the lateral distribution of vegetation biomass along the inner bank, while higher flows than a threshold $Q_{t}$ (named 'floods') are assumed able to modify the channel bed morphology and to cause outer bank erosion. Simplified relations are adopted to describe sedimentation generated by the interaction between plants and river flow, and their effect on sediment mobility. In particular, by stabilizing the fluvial sediments through root systems, vegetation within the inner bank determines the width of the morphologically active portion of the cross-section, thus generating a feedback effect on river bed morphology. For each flood event, an estimate of eroding bank retreat and the 
new transverse bed profile in the active river channel is obtained by applying an analytical meander morphodynamic model. The interplay between flow and riparian vegetation is described by interpreting the temporal oscillations of the water stage as a stepwise sequence of steady states with a local uniform flow assumed at each stage. The model allows sediments at the inner bank to be either eroded or deposited. The model's different components are detailed below.

\subsection{Assessment of 'low flow' and 'flood' conditions}

Quantitative bio-morphodynamic models for the study of the mutual interaction between vegetation and river processes need to account for temporal streamflow variability (Camporeale and Ridolfi, 2006, 2010). However, analytical solutions for the flow field and bed topography in meandering rivers almost always have been derived for an ideal channel fed with a 'formative' constant discharge (Pittaluga \& Seminara, 2011). In order to apply analytical meander models to our intrinsically unsteady biomorphodynamic problem, we chose to partition the input hydrographs into two fundamentally different flow conditions, under which distinct rules hold, aiming to retain only the main processes occurring under each condition and to account for the related difference in the relevant time scales. Therefore a threshold discharge value $Q_{t}$ has been introduced to separate between 'low flows' and 'floods'. During 'low flows' the interactions between sediment, flow and vegetation may determine variation in river channel bed topography, while during 'floods' outer bank erosion can occur and morphological changes of the channel bed are mainly controlled by channel curvature. While we are aware that such a threshold introduces a strong simplification of the actual processes, it forms a reasonable choice that is coherent with our aim of keeping the modelling approach at the highest meaningful level of simplicity. Therefore, the choice of $Q_{t}$ partitions the input streamflow time series into a discrete number of 'formative events'. Without loss of generality, we have expressed $Q_{t}$ as a percentage, $\alpha_{Q}^{*}$, of the maximum discharge value, $Q_{\max }$, of the analysed record, such that:

$$
Q_{t}=\alpha_{Q}^{*} Q_{\max }
$$

For each discharge value above the computed threshold $Q_{t}$, the morphodynamic sub-model (Section 2.5) is applied to the morphologically active portion of the cross-section to compute the outer bank shear stress and thus the bank retreat through the bank erosion submodel (Section 2.6). At the end of each formative event, the river channel bed is re-shaped to correspond to equilibrium conditions with a representative discharge value for the flood event, computed as the average of discharge values exceeding the threshold $Q_{t}$ during the event.

\subsection{Riparian vegetation dynamics sub-model}

Flow, sediment transport and riparian vegetation co-evolve through mutual feedback processes, which are accounted for as interacting unit processes. Flow and sediment transport affect riparian vegetation through erosion of vegetated areas, provision of water and nutrients to support vegetation growth, and provision of exposed sediments for colonization by pioneer species. Conversely, riparian vegetation affects river channel morphodynamics by moderating erosion processes and enhancing sediment deposition.

\section{River controls on riparian vegetation dynamics}

For this model component, it was assumed that riparian vegetation biomass tends to a local maximum, $b_{e q}$, which is a function of the position in the vertical frame. The vertical distribution of such 'carrying capacity', proposed by Marani et al. (2013), was adopted to model this tendency: 


$$
b_{e q}(\eta)=2 B_{0}\left[\exp \left(\lambda_{1}\left(\eta-\eta_{0}\right)\right)+\exp \left(\lambda_{2}\left(\eta-\eta_{0}\right)\right)\right]^{-1}
$$

where $\eta$ denotes the local ground elevation, $B_{0}$ is a scaling factor for the vegetation biomass density, and $\lambda_{1}, \lambda_{2}$ quantify the rate at which vegetation fitness decays from its maximum, which is reached at an optimal elevation that depends on $\eta_{0}$. This refers to ideal conditions of moisture availability expressed as distance from an assumed horizontal water table, which can be adjusted to model different groundwater conditions or different types of vegetation. Larger values of $\lambda_{1,2}$ denote more specialized vegetation, able to grow to an optimum biomass within a narrow range of land surface elevations. Relation (3) is rewritten in dimensionless form as:

$$
b_{e q}^{*}(\eta)=b_{e q}(\eta) / b_{e q, \max }
$$

with $b_{e q, \max }$ representing the maximum value of $b_{e q}$. Despite the fact that equation (3) was initially proposed for tidal systems, it also fits the case of fluvial environments (Bertoldi et al., 2014). Through the adjustment of parameters $\lambda_{1,2}$, two hydrological mechanisms that affect the lateral distribution of riparian vegetation can be accounted for: the destructive action of river flow and the control of sediment moisture due to the water table depth.

In order to model the temporal evolution of the vegetation biomass over the cross-section, a dichotomous model similar to that proposed by Camporeale and Ridolfi (2006) was adopted. Vegetation growth during the exposed period $(h<\eta)$ is modelled as a function of moisture availability through equation (5). Vegetation decay during floods $(h>\eta)$ is related to the negative effects induced by the flow on vegetation (e.g. uprooting, anoxia, burial) and is modelled through equation (6):

$$
\begin{array}{ll}
\frac{d b^{*}}{d t}=\sigma\left(b_{e q}^{*}-b^{*}\right)^{m_{1}} & h<\eta \\
\frac{d b^{*}}{d t}=-\gamma b^{* m_{2}}(h-\eta) & h \geq \eta
\end{array}
$$

In equations (5)-(6), $t$ denotes time, $b^{*}$ denotes the local biomass, $m_{1}$ and $m_{2}$ are speciesdependent coefficients, $\sigma$ and $\gamma$ represent the biomass growth $\left(\right.$ day $\left.^{-1}\right)$ and decay rates $\left(\right.$ day $\left.^{-1} \mathrm{~m}^{-1}\right)$, respectively. The parameters $\sigma, \gamma, m_{1}, m_{2}$ also depend on the species characteristics and on the environmental conditions, requiring in situ field information for their correct setting in a model application that is targeted to a specific case. Moreover, $m_{1}$ and $m_{2}$ are numerical parameters that allow the shape of the vegetation growth curve to be adjusted (i.e. convex/concave), in order to account for the growth rate that characterizes the plants in their early growth phase. Here we assumed that $m_{1}=m_{2}=1$. Finally, the water depth was introduced in equation (6) in order to account for the stronger impact associated with a high local water depth, for example an increase in shear stress.

\section{Vegetation feedbacks on flow and sediment transport}

The interaction between riparian vegetation and over-bank flow associated with root reinforcement of the soil is a fundamental mechanism in the evolution of the floodplain and in the lateral migration of river banks. In particular, the presence of pioneer plants or deposited large wood affect depositional and erosional patterns and initiate distinctive landforms that, in the case of meanders, can result in scroll formation (Nanson, 1981; Gurnell et al., 2001; Nakayama et al., 2002). These 
effects are quantitatively reproduced in the model through two simplified mathematical relations. The first accounts for the active role played by riparian plants in inducing sedimentation:

$$
\frac{d \eta(n)}{d t}=\alpha_{\text {sed }} b^{*}(n) D(n)
$$

where $\alpha_{\text {sed }}$ is the deposition rate (expressed in $d a y^{-1}$ ), which can be estimated from field and laboratory observations (e.g. Walling and He, 1998; van Dijk et al., 2013). For the present modelling, we assumed $\alpha_{\text {sed }}=1$ day $^{-1}$; with such a value, the range of overall deposition rates obtained in the simulations that will be discussed in Section 3 ranges around $15-30 \mathrm{~mm} / \mathrm{year}$, depending on flood characteristics (e.g. duration and intensity). The deposition rate $\alpha_{\text {sed }}$ in equation (7) implicitly accounts for different concentrations of fine, suspended sediment within the local water column: for a fixed sediment concentration, the deeper the local water depth, the larger the volume of sediment that can be potentially deposited on the ground surface. Moreover, well developed vegetation (higher values of $b^{*}$ ), by trapping the sediments and modifying the flow field, induces the sedimentation of a larger amount of sediments compared to that deposited in association with young plants (lower values of $b^{*}$ ). Although the model does not explicitly include suspended load equations, this closure relationship allows us to capture the basic physics of the sedimentation process.

Reduced sediment mobility due to root system development is accounted for by introducing a dependence of the threshold value of the Shields parameter $\vartheta_{c}^{*}(n)$ on the local vegetation biomass density $b^{*}(n)$ :

$$
\vartheta_{c}^{*}(n)=\vartheta_{c s}^{*}+\vartheta_{c v}^{*} b^{*}(n)^{\alpha_{t}}
$$

where $\vartheta_{c S}^{*}$ is the threshold value for incipient movement in the case of bare sediments (typically taken as 0.047 in the classical bedload relation of Meyer-Peter and Muller, 1947), $\vartheta_{c v}^{*}$ represents the increase in sediment stability due to the presence of roots, and $\alpha_{t}$ is a coefficient that depends on the development stage of the roots and can vary from 0 to 1 . The biomass distribution shows an increasing value with distance from the river edge. Therefore, a low value of vegetation biomass can be associated with young plants. Thus, $\alpha_{t}$ was set to 0.5 to obtain a stronger sediment reinforcement effect during the initial stages of vegetation growth. A value of $\vartheta_{c v}^{*}=0.2$ was assumed (in accordance with Bertoldi et al., 2014), which implies a maximum increase of the critical Shields parameter for sediment motion $\vartheta_{c}^{*}$ to 0.247 when $b^{*}=1$. However, the condition $b^{*}=1$ corresponds to the theoretical maximum (Equation 4 ) and is hardly reached during the simulations.

Changes in roughness associated with the presence of vegetation were accounted for by varying the Strickler coefficient according to the following linear relation:

$$
k_{s}(n)=k_{s g}+\left(k_{s v}-k_{s g}\right) b^{*}(n)
$$

where $k_{s g}$ and $k_{s v}$ are the Strickler coefficients associated with bare sediments and with fully developed vegetation, respectively. In the present analysis, we assumed $k_{s g}=30 \mathrm{~m}^{1 / 3} \mathrm{~s}^{-1}$ and $k_{s v}=17 \mathrm{~m}^{1 / 3} \mathrm{~s}^{-1}$ in order to account for the increase in flow resistance due to vegetation, which can be considered representative of gravel-bed rivers.

\subsection{Quasi-1D hydraulic sub-model}

Water stage values associated with the input hydrograph are computed using a quasi-1D hydraulic model over an assigned morphology. The model is quasi-1D because longitudinal and vertical 
variations are neglected, together with several processes along the transverse direction, which is the only considered spatial coordinate. In particular, the water stage and streamwise flow velocity $U(n)$ are estimated for each discharge value $Q$ by partitioning the cross-section into vertical strips where local uniform flow conditions are assumed (Lotter, 1933; Engelund, 1964):

$$
\begin{gathered}
U(n)=k_{S}(n) D(n)^{2 / 3} \sqrt{S} \\
Q=\int U(n) D(n) d n
\end{gathered}
$$

where $k_{s}(n)$ can be influenced by the vegetation biomass according to equation (9), and $S$ is the longitudinal slope of the channel, assumed equal to that of the floodplain. This approach is strictly valid under the assumptions of: i) laterally horizontal water surface; ii) laterally constant longitudinal slope $S$ across the transect; and iii) negligible lateral shear stress between adjacent strips with respect to the near-bed shear stress.

Estimated local water depth values provide one input to the submodel for riparian vegetation dynamics (Section 2.3; see equations (5) and (6)) and to compute the local values of the Shields parameter $\vartheta^{*}(n)$ (equation (1)). The water stage is also used to establish the portion of the morphologically active cross-section, consisting of the strips where $\vartheta^{*}(n)$ exceeds the critical value for sediment mobility $\vartheta_{c}^{*}(n)$, i.e. the region where:

$$
\vartheta^{*}(n)>\vartheta_{c}^{*}(n)
$$

This allows an active width of the transect to be computed for every discharge value. This computation reflects the action of riparian vegetation on both sediment mobility and flow roughness: the critical Shields stress value $\vartheta_{c}^{*}(n)$ accounts for the effect of laterally variable soil resistance to erosion due to vegetation and it is estimated through relation (8). Moreover, the local Shields parameter $\vartheta^{*}(n)$ is indirectly affected by vegetation in the wet areas through its indirect dependency on flow roughness (equation (9)) through the water depth.

Channel bed morphodynamics and lateral bank migration are not modelled at 'low flow' stages, when changes in bed elevation are restricted to the depositional processes induced by the interaction between vegetation and flow during the inundation period (equation (7) in Section 2.3).

\subsection{Meander bend morphodynamic sub-model}

The meander bend morphodynamic sub-model consists of a 3D nonlinear model for flow and bed deformation in a bend of constant curvature. It is essentially based on the model proposed by Seminara and Solari (1998), which is slightly adapted to account for the lateral roughness variability associated with the possible presence of vegetation in the channel region.

More specifically, local water depth values $D(n)$ correspond to the first order solution denoted with $D_{0}(n)$ in Seminara and Solari (1998), and are obtained through a procedure that is almost identical to the one described in their Section 3.1 and 3.2, with the exception of their equations 20 and 21 where the laterally variable no slip reference level $\xi_{0}(n)$ is affected by vegetation biomass $b^{*}(n)$ in the channel region through the lateral variation of the friction coefficient $C_{f}^{*}(n)$ :

$$
C_{f}^{*}(n)=\left[6+2.5 \ln \frac{D_{u}(n)}{2.5 d_{s}}\right]^{-2}
$$


where $D_{u}(n)$ is the local water depth associated with the uniform flow that accounts for an increase in bed roughness due to the presence of plants (see Section 2.3, equation (9)) within the active portion of the river cross-section. In equation (12) $C_{f}^{*}(n)$ is related to the Strickler relation through $C_{f}^{*}(n)=\left[k_{s}(n) D_{u}(n)^{1 / 6} g^{-1 / 2}\right]^{-2}$.

The near-bank longitudinal shear stress $\tau_{s}(n)$ is then computed as

$$
\tau_{s}(n)=\sqrt{C_{f}^{*}(n)} N\left(\xi_{0}\right) \hat{u}^{2} F(\xi, n)_{, \xi} \xi_{\xi_{0}}
$$

where $N$ is the vertical distribution of the eddy viscosity assumed to coincide with the classical parabolic distribution for uniform flows corrected by Dean's (1974) wake function, $\xi$ is the normalized vertical coordinate, and $\hat{u}$ is the mean value of the longitudinal component of the uniform flow. In equation (13) the function $F(\xi, n)$ represents the velocity distribution of the local uniform flow.

For every flood event detected in the input hydrograph $\left(Q>Q_{t}\right.$; see Section 2.2), the meander bend sub-model is applied several times over the morphologically active portion of the cross section. First, it is used to compute the longitudinal bed shear stress close to the outer bank, which is required by the bank erosion sub-model (Section 2.6) to estimate lateral bank migration. Second, it is used to adjust the lateral channel bed profile at the end of the formative event to the one corresponding to equilibrium conditions with the updated channel width value.

\subsection{Bank erosion sub-model}

The outer banks of meandering rivers typically present a cohesive top layer, often related to the presence of vegetation, and a non-cohesive bottom layer (Lauer \& Parker, 2008). During a flood event, the action of fluvial erosion on the lower layer undermines the upper one possibly leading to its failure. The resulting presence of blocks of cohesive sediment at the bank toe increases the bank resistance to erosion, reducing the rate of bank retreat (Parker et al., 2011). Such a complex process of bank retreat is often parameterized in morphodynamic models through an erosion coefficient. Here the rate of the outer bank lateral erosion, $\zeta$, is modelled following the established approach (e.g. Darby et al., 2002; Constantine et al., 2009) through the excess shear stress relation

$$
\zeta=M\left(\tau-\tau_{c}\right)
$$

where $\tau(\mathrm{Pa})$ is the longitudinal shear stress computed at the toe of the external bank (computed through equation (13)), $\tau_{c}$ represents the critical stress threshold for bank sediment transport, and $M\left(m^{3} N^{-1} s^{-1}\right)$ is the erosion coefficient that accounts for the biophysical characteristics of the river bank (sediments and presence of vegetation) and can be estimated from field measurements (Darby, et al., 2007; Constantine, et al., 2009; O'Neal and Pizzuto, 2011). By including relation (14) into the model, we implicitly assume that material eroded at the outer bank is immediately transported out of the section. This assumption is consistent with the hypothesis of negligible net sediment flux between the channel and the floodplain region, which is imposed by most analytical morphodynamic models.

\subsection{Simulation set}

The mutual feedbacks between river hydro-morphodynamics and riparian vegetation dynamics can be expected to give rise to different evolutionary scenarios under different flow regimes (Gurnell et al., 2001; Braudrick et al., 2009; Perona et al., 2012) and under varying environmental controls on riparian vegetation establishment and growth. Simulations were organized into two sets: a first set 
where the river channel was fed with an idealized hydrograph and a second set that tries to mimic a real case of meander bend evolution. To disentangle the role of different river hydrological properties such as flood magnitude, frequency, duration and seasonal regularity, we investigated their effect separately through the simplified input hydrographs shown in Figure4. The idealized regular hydrograph of Figure $4 \mathrm{~A}$ is set as the reference case; other input hydrographs have been developed by either increasing flood magnitude (Figure 4B), extending flood duration (Figure 4C), decreasing flood frequency (Figure 4D), or simultaneously varying these parameters to generate a less regularly fluctuating pattern (Figure 4E). All the hydrographs reported in Figure 4 were discretized using a daily time step. Furthermore, the reference and the irregular scenarios (Figure 4A and Figure $4 \mathrm{E}$, respectively) were applied to two different environmental conditions: an environment suitable for vegetation growth ('good') and another where flow forcing prevented the establishment of colonizing plants ('bad') by adjusting the parameter $\gamma$ expressing vegetation decay. The adopted values were $\gamma=0.017 \mathrm{day}^{-1} \mathrm{~m}^{-1}$, where conditions are highly suitable for vegetation colonisation and establishment, and $\gamma=0.5 \mathrm{day}^{-1} \mathrm{~m}^{-1}$, where riparian plant colonization and development is limited (see, e.g., Gurnell et al., 2012). The initial value of the channel width was fixed at $80 \mathrm{~m}$, which is larger than the value obtained through the empirical regime formula of Parker et al. (2007), using both the threshold $Q_{t}$ and the maximum discharge value $Q_{\max }$. Such choice has been a-posteriori checked not to affect results. Hereinafter we will refer to this channel as an over-wide (OW) channel, while for the case in which the initial channel width is lower than the predicted regime value we will use the term over-narrow $(\mathrm{ON})$, following the terminology already used by Eke et al. (2014).

Four long-term simulations (120 years) were conducted with the same reference scenario hydrograph to assess the dependence of the model outcomes on different choices for the imposed initial channel width (using an over-narrow channel $40 \mathrm{~m}$ wide in addition to the reference width) and vegetation environmental conditions (considering the two values of $\gamma$ ).

Table 1 summarizes the experimental conditions of all the performed simulations. Each run is identified by an acronym, where the first two letters identify the input hydrograph type and the last letter stands for the environmental condition with respect to vegetation suitability ( $G=$ good and $B$ $=$ bad). 

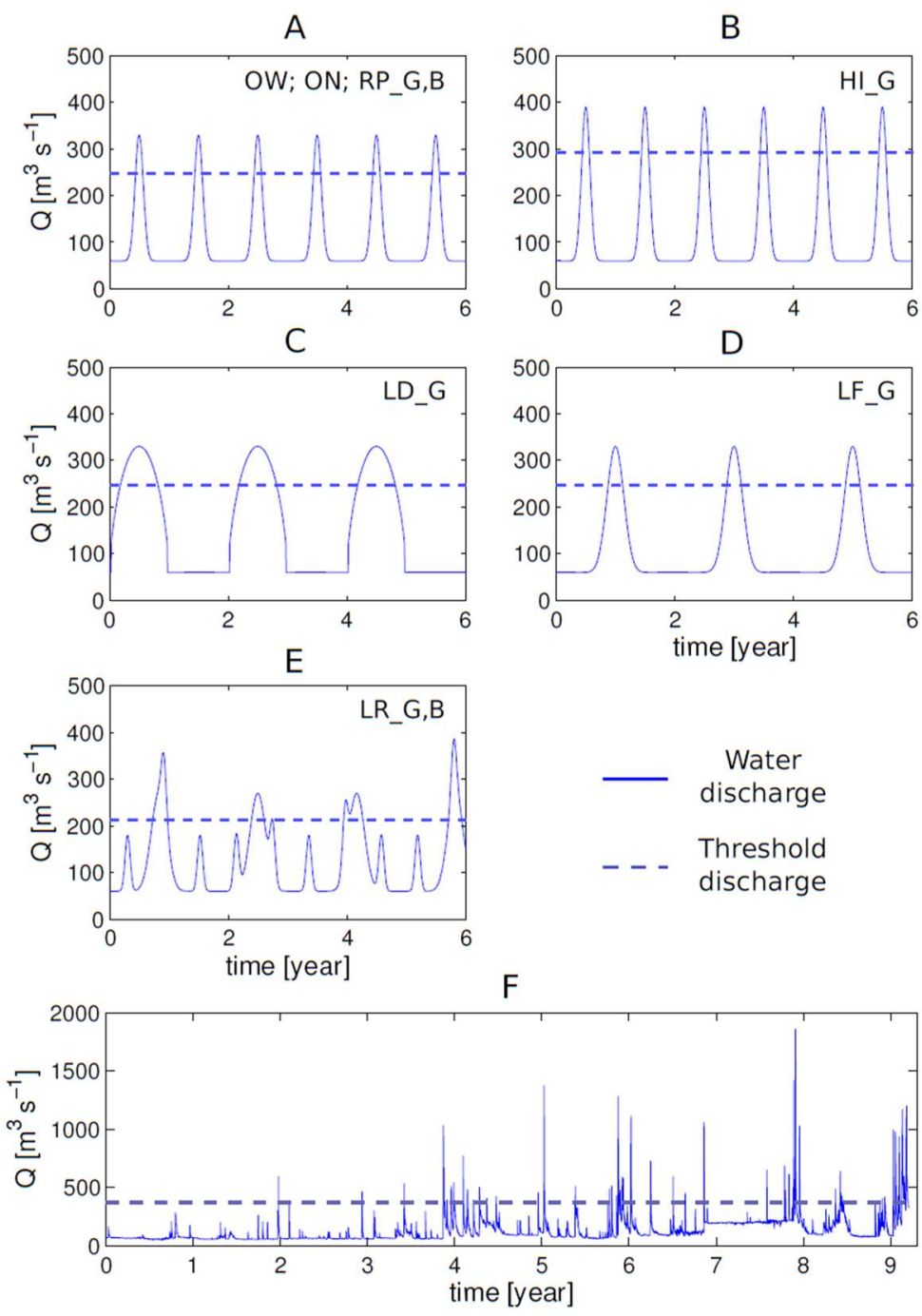

Figure 4 Hydrographs used in the simulation runs: A) periodic discharge variation, taken as reference case; B) sequence analogous to A) but with an increasing intensity; C) variation in duration; D) variation in frequency (event every 2 years); E) discharge fluctuations with changes in frequency and intensity; and F) historical data set. The codes in each panel A to $E$ denote the ID of the numerical runs performed with the corresponding hydrograph (Table 1 ). 
Table 1 Properties of the different numerical experiments. $\mathrm{G}=$ good, $\mathrm{B}=$ bad environment for vegetation growth, $\mathrm{RP}=$ reference periodic, $\mathrm{LR}=$ less regular, $\mathrm{HI}=$ higher intensity, $\mathrm{LD}=$ longer duration, $\mathrm{LF}=$ low frequency, $\mathrm{OW}=$ over-wide channel, $\mathrm{ON}=$ over-narrow channel.

\begin{tabular}{ccccc} 
ID run & $\begin{array}{c}\text { Input } \\
\text { Hydrograph }\end{array}$ & $\begin{array}{c}\text { Run Duration } \\
\text { [year] }\end{array}$ & $\begin{array}{c}\gamma \\
{\left[\mathrm{day}^{-1} \mathrm{~m}^{-1}\right]}\end{array}$ & $\begin{array}{c}\text { Initial width } \\
{[\mathrm{m}]}\end{array}$ \\
\hline OW_G & Figure 4A & 120 & 0.017 & 80 \\
RP_G & Figure 4A & 40 & 0.017 & 80 \\
RP_B & Figure 4A & 40 & 0.2 & 80 \\
LR_G & Figure 4E & 40 & 0.017 & 80 \\
LR_B & Figure 4E & 40 & 0.2 & 80 \\
HI_G & Figure 4B & 40 & 0.017 & 80 \\
LD_G & Figure 4C & 40 & 0.017 & 80 \\
LF_G & Figure 4D & 40 & 0.017 & 80 \\
OW_B & Figure 4A & 120 & 0.5 & 80 \\
ON_G & Figure 4A & 120 & 0.017 & 40 \\
ON_B & Figure 4A & 120 & 0.5 & 40 \\
\hline
\end{tabular}

All the other parameters were kept constant in the performed runs, namely: $M=$ $10^{-6} \mathrm{~m}^{3} \mathrm{~N}^{-1} \mathrm{~s}^{-1}, k_{s g}=30 \mathrm{~m}^{1 / 3} \mathrm{~s}^{-1}, k_{s v}=17 \mathrm{~m}^{1 / 3} \mathrm{~s}^{-1}, \vartheta_{c v}=0.2, \alpha_{\text {sed }}=0.003$ day $^{-1}, \sigma=$ $0.00625 \mathrm{day}^{-1}, \lambda_{1}=6 \mathrm{~m}^{-1}, \lambda_{2}=0.4 \mathrm{~m}^{-1}, \eta_{0}=0.5 \mathrm{~m}, S=0.001, d_{50}=0.02 \mathrm{~m}$. The value of the channel slope $S$ was set in order to be consistent with the sediment size adopted for the simulations, providing a realistic combination for gravel bed rivers.

Finally, two runs were performed to explore model predictions when applied to a field case. For this purpose we used a cross-section of the meandering lower Tagliamento River, northeast Italy. The River Tagliamento is a large gravel bed river with a corridor extending from the Alps to the Adriatic sea. Along its course the river shows different planform styles, from multi-thread in the upper and middle reaches to transitional and single thread / meandering in the lower reaches. Furthermore, as a result of relatively light human pressures, the river has preserved a quite natural riparian zone compared to other river systems in the area (Tockner et al., 2003; Bertoldi et al., 2009).

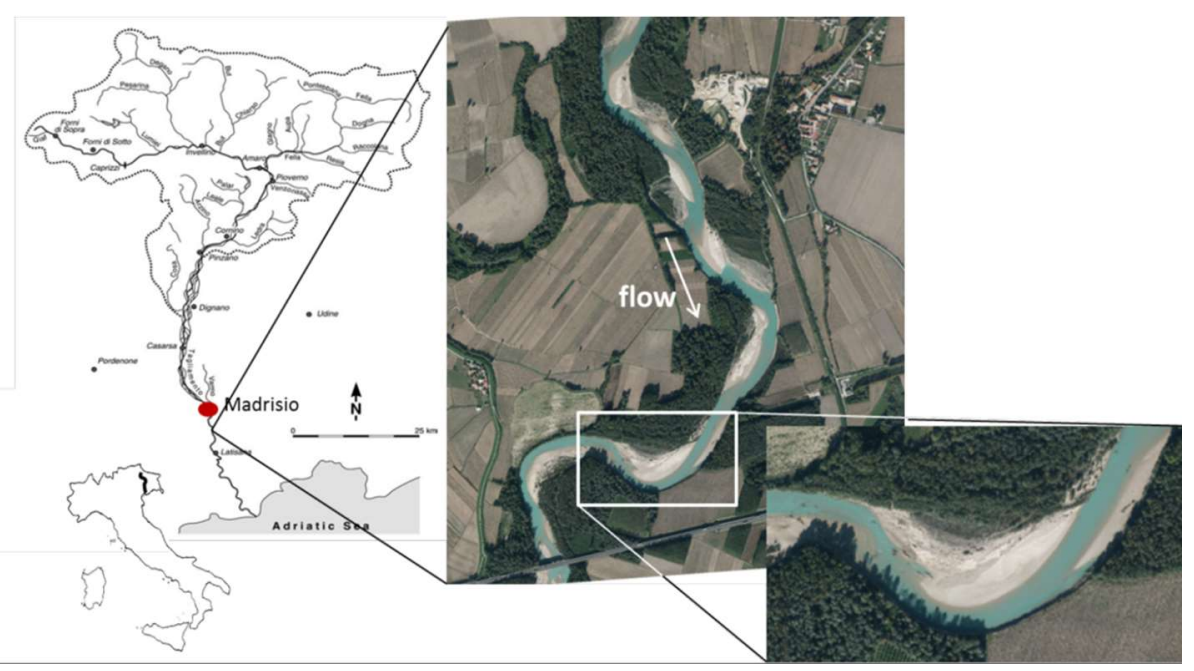

Figure 5 Map with location of the study site of the lower Tagliamento River. The aerial photograph illustrates the channel morphology in 2012 (courtesy of Surian N., Department of Geography, University of Padua, Italy) 
The initial transect geometry was extracted from a 2001 LiDAR survey. Because a discharge record value is not available for the study reach, the input hydrograph was estimated from the historical water stage record available at the Madrisio gauging station located a few $\mathrm{km}$ upstream (see Figure 5) by assuming a sequence of uniform flow conditions (see Figure 4F). The values obtained were then transformed into daily records by averaging the data recorded every hour. The coefficient $\alpha_{Q}^{*}$, that separates low flow from flood conditions, was set to 0.2 in order to associate significant changes in channel bed morphology to discharge values that are coherent with existing studies focussing on the same site of the Tagliamento River (e.g. Surian et al., 2009). The classical hydraulic parameters i.e. $k_{s g}, S$ and $d_{50}$, as well as the coefficients $\sigma$ and $\gamma$ that describe riparian vegetation dynamics, were derived from field observations at the site (see Zen, 2014) and integrated with data available in the literature (e.g. the lateral biomass distribution for different species: Johnson et al., 1995; Camporeale and Ridolfi, 2006). Furthermore, the increased resistance of the deposited sediments to erosion due to the development of plant root systems was estimated based on the few references available (see Bertoldi et al., 2014). Two different simulations were performed, referring to the period 2001 - 2014. In the first simulation the erosion coefficient $M$ and the sedimentation parameter $\alpha_{\text {sed }}$ were adjusted to match, respectively, the position of the outer bank and the elevation of the floodplain observed in the 2014 cross-section. The predicted bed transect at the end of the simulation was compared with the surveyed transect topography in 2014. A second simulation was aimed at analysing the effect of bank protection structures to prevent outer bank erosion on the biomorphodynamic evolution of the system. This second test was almost identical to the previous one but for the presence of bank protection structures starting after 10 years of evolution. This effect was modelled by setting the value of the coefficient $M$ (equation (14)) to zero.

The set of the parameters used for the application to the real case is as follows: $M=$ $3 \cdot 10^{-7} \mathrm{~m}^{3} \mathrm{~N}^{-1} \mathrm{~s}^{-1}, k_{s g}=40 \mathrm{~m}^{1 / 3} \mathrm{~s}^{-1}, k_{s v}=15 \mathrm{~m}^{1 / 3} \mathrm{~s}^{-1}, \vartheta_{c v}=0.2, \alpha_{\text {sed }}=0.015 \mathrm{day}^{-1}, \sigma=$ 0.008 day $^{-1}, \gamma=0.017 \mathrm{day}^{-1} \mathrm{~m}^{-1}, \lambda_{1}=6 \mathrm{~m}^{-1}, \lambda_{2}=0.4 \mathrm{~m}^{-1}, \eta_{0}=1.3 \mathrm{~m}, S=0.001, d_{50}=$ $0.02 \mathrm{~m}$.

\section{Results}

\subsection{Biomorphodynamics of a laterally migrating meander bend}

The model provides a physically based description of the lateral evolution of a constant curvature meander bend in the presence of riparian vegetation. To illustrate typical results, we refer to a longterm (120 years) simulation under periodic discharge variations (OW_G in Table 1, see Figure 6). Because the bend morphodynamics sub-model is applied for each discharge value above the imposed threshold, every flood event is described by several values that are shown in the graphs as a cloud of points (see Figure 6B, C, D). However, in order to correctly interpret a possible evolutionary trend of the system, the mean value has been assumed as representative for each event (red line in Figure 6B, C, D). For visual clarity, the results are displayed using their average value and, in the following, the cloud of points generated from each step of the simulation will be omitted. Similarly, the temporal evolution of vegetation is investigated focusing on the maximum values during each event, as in the example presented in Figure 6E. The position of the initial inner bank as well as that of the evolving outer bank is represented through a vertical dashed line, whose height does not bear any physical meaning in the results presented. 
The key biophysical dynamics reproduced by the model can be illustrated by analysing the reference run OW_G. At the start of each simulation, the channel is represented as a rectangular cross section between the two banks (positioned at -40 and $40 \mathrm{~m}$ in the case of an $80 \mathrm{~m}$ wide initial channel) and characterized by a flat bed ( $0 \mathrm{~m}$ elevation). After the first formative event, the flow field induced by channel curvature (scour/deposition at the outer/inner bank) modifies the transverse bed slope of the river channel, generating the classical cross-section of a meander bend (refer to time $t_{0}$, solid thin line, in Figure 6A). Since the section at $t_{0}$ in Figure 6A represents the first physically meaningful configuration of the evolution process, we have omitted the arbitrary rectangular initial geometry from the sequence of cross-sections illustrated in Figure 6A.

During low flow conditions following the first event, riparian vegetation colonizes and consolidates the exposed sediments of the channel bed. The subsequent increase in water stage during a new flood determines sediment deposition or plant removal in the vegetated area. When the threshold discharge is exceeded, the longitudinal shear stress at the outer bank is estimated and bank retreat is computed. At the end of each event the channel bed is updated according to the average value of the discharges that exceeded the threshold during the flood event. The procedure is repeated for all events within the simulation period. As a result, the inner bank develops a rather complex geometry and the channel bed elevation increases progressively (see Figure 6D), both because of sediment deposition and a reduction of the shear stress (see Figure $6 \mathrm{C}$ ) that leads to a less pronounced scour at the outer bank (see Figure 6A).

The spatial structure of the cross-section obtained at the end of the run (solid thick brown line in Figure $6 \mathrm{~A}$ ) is representative of all simulated transects. Starting from the outer bank and moving inwards, first a channel region composed of bare sediments can be found (from 400 to $480 \mathrm{~m}$, approximately); this is followed by an advancing floodplain region, located between 260 and $400 \mathrm{~m}$, where vegetation, flow and sediments interact leading to a corrugated surface; and last, an almost flat, stable floodplain region is found farther from the river channel.

The interplay between the channel and the advancing floodplain region controls the temporal evolution of the active channel width and highlights the roles of opposite bank dynamics. Bank erosion initially increases the channel width, reaching $85 \mathrm{~m}$ on average during the first formative event from an initial channel width of $80 \mathrm{~m}$ (Figure 6B). Depth is reduced in a wider channel, and hence the shear stress diminishes, together with channel bank lateral erosion (Figure $6 \mathrm{C}$ ). These conditions allow vegetation to establish at the inner bank (Figure 6E), promoting channel narrowing that lowers the active channel width to approximately $65 \mathrm{~m}$ in a few years. After about 40 years the width slightly increases and fluctuates around a value of $70 \mathrm{~m}$ reflecting a condition of dynamic equilibrium to which the initially over-wide channel tends in its evolution (Figure 6B). The model suggests that such temporal fluctuations are intrinsically associated with flow unsteadiness, which generates a periodic sequence of modifications eventually resulting in net channel migration. Each width oscillation is characterized by the same process sequence: (i) channel width increases due to outer bank erosion, as a consequence (ii) the water depth decreases, and therefore (iii) extends the portion of the cross section available for vegetation recruitment, thus (iv) promoting the consolidation of the inner bank. Considering the stabilizing role played by vegetation, this four stage sequence leads to a progressive reduction in the morphologically active channel width under flood conditions. This mutual feedback (already argued by Nanson, 1981 as a 'dance') between the two river banks is well reproduced by the curve of the mean values shown in Figure 6B (continuous line). Here, active channel widening due to outer bank erosion during high flows is identified by a segment with positive slope, while the loss of active area associated with inner bank accretion is identified by a negative slope.

Output parameters directly depending on the interaction between vegetation and river processes (i.e. active width, average channel bed elevation) show a less regular pattern compared 
to that directly influenced by the hydrological conditions and only indirectly by bio-morphological interactions (such as near-bank shear stress and overall biomass). Figure 6 shows that all these parameters oscillate with the same 1 year frequency that characterizes the input hydrograph (Figure 4A). However, the amplitude of oscillations is rather regular for vegetation biomass and outer bank shear stress (Figure 6C and 6E), while variations in channel active width and the bed average elevation fluctuate with more irregular amplitudes (Figure 6B and 6D).
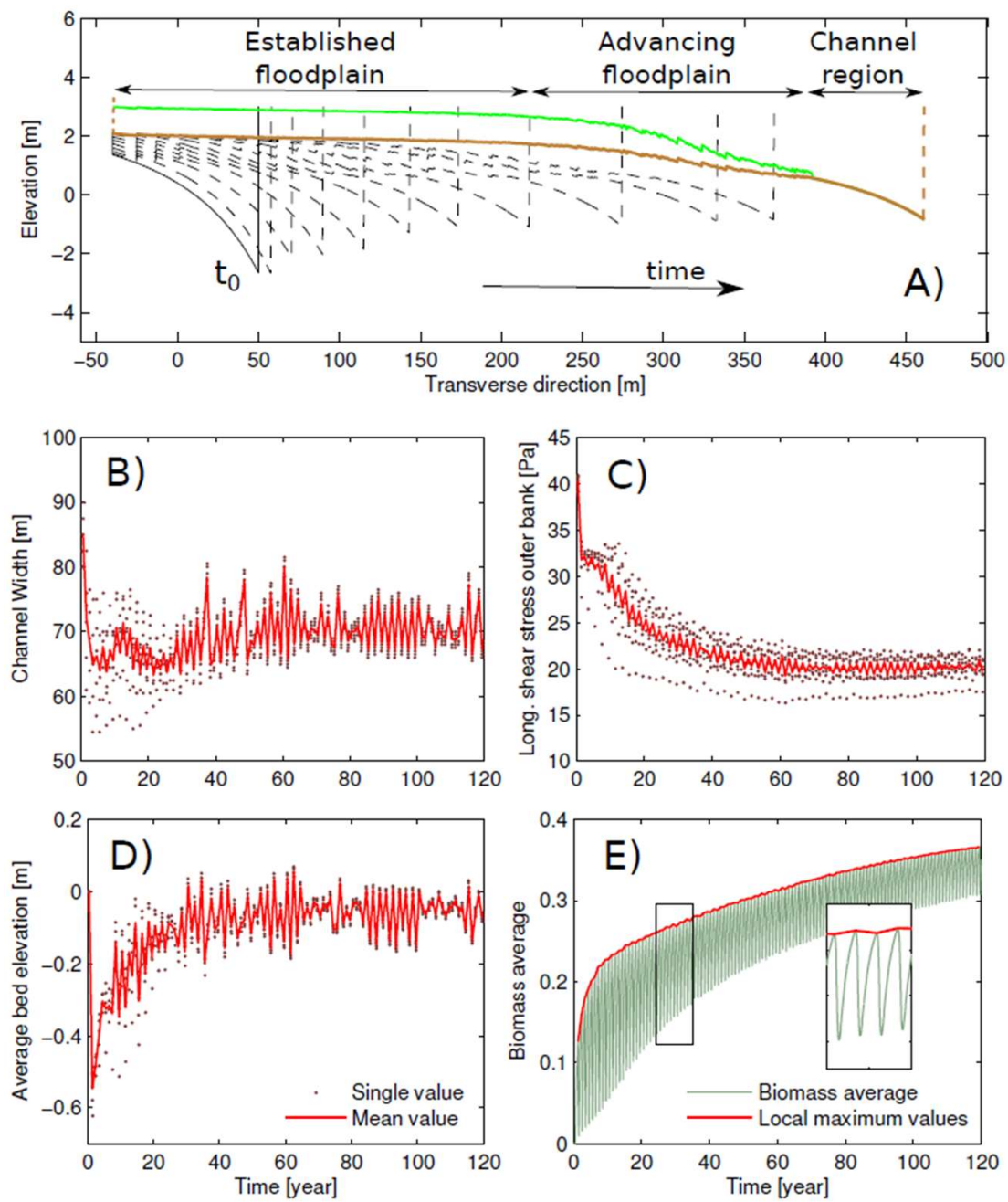

Figure 6 Long-term simulation (120 years, OW_G in Table 1) under periodic discharge variation (Figure 4A): A) cross section temporal changes (dashed line) with the final cross-section (brown solid line) and the related biomass distribution (green solid line, the vertical scale is qualitative). Temporal variation of: $B$ ) active channel width, C) longitudinal shear stress at the outer bank, D) average bed elevation of the active width, E) overall biomass (entire cross section). In the subplots B, C, D, the red thick line indicates the average value for each formative flow, while in E) it corresponds to the local peaks in biomass event-scale fluctuations.

\subsection{Controlling factors on cross-sectional biomorphodynamics}

Results obtained from the above long-term simulation illustrate the interaction between riparian vegetation, sediments and river flow in driving river channel morphodynamics. In light of this, further analyses were conducted for a relative short period of 40 years, to assess the possible role of different hydrological and environmental factors on the biomorphodynamic evolution of the system. Two contrasting environmental scenarios were investigated to simulate a suitable environment for riparian vegetation growth $\left(\gamma=0.017 \mathrm{day}^{-1} \mathrm{~m}^{-1}\right)$ and the case in which vegetation biomass development is severely inhibited $\left(\gamma=0.2\right.$ day $\left.^{-1} \mathrm{~m}^{-1}\right)$. In the following 
analysis, we will refer to the former case as 'vegetated', and the latter as 'unvegetated', although vegetation may be present. The effect of flood regularity, magnitude, frequency and duration, as well as the effect of imposing different initial channel width are also investigated (see the list of runs in Table 1).

Results that refer to the role of environmental and hydrologic controls are shown in Figure 7. The Figure shows the cross-section profile (brown thick line) and the related vegetation biomass (green line) at the end of every simulation, each referring to 40 years of bio-morphological changes. Simulations with favourable conditions for vegetation $\left(\gamma=0.017 \mathrm{day}^{-1} \mathrm{~m}^{-1}\right.$, Figure 7 RP_G, LR_G, HI_G, LD_G, LF_G) clearly reveal the occurrence of an advancing floodplain region and a channel region as two rather distinct zones: the advancing floodplain has a higher elevation and is colonized by vegetation (on the left), while the channel is characterized by bare sediments (on the right). The latter zone represents the morphologically active river cross-section during the last flood, whereas the former identifies the newly constituted inner bank. The advancing floodplain region is much less distinct from the channel region for simulations in which vegetation growth is strongly inhibited $\left(\gamma=0.2\right.$ day $^{-1} \mathrm{~m}^{-1}$; Figure $\left.7 \mathrm{RP} \_\mathrm{B}, \mathrm{LR} \_\mathrm{B}\right)$. An almost smooth ground surface develops within the inner bank without appreciable topographic oscillations and the total biomass is much smaller, making the role of vegetation almost negligible.

In all runs with favourable vegetation conditions, ground topography and biomass appear to oscillate at two different spatial scales: a short scale, associated with event-scale lateral shifting of the bend and reflected by the corrugation of the biomass and ground topography plots in Figure 7; and a longer scale, of the same order of magnitude as the channel width, which is highlighted by the black horizontal arrows in Figure 7.

Comparison of the different cases presented in Figure 7 suggests the potential relevance of hydrologic controls on inner bank advance and on the related topographical and vegetation patterns. Namely, irregularity of flood events (LR_G) produces, as might be expected, more irregular spatial biomass and ground topography oscillations, reflecting a more irregular oscillation in the active channel width. Moreover, the width scale patterns in the advancing floodplain region almost disappear. Higher flood magnitude (HI_G) and, to a lesser extent, longer flood duration (LD_G) produces wider channels compared to the reference run (RP_G). A decrease in flood frequency (LF_G) and an increase in flood duration (LD_G) almost remove the small scale biomass and topographic oscillations observed in the reference and other runs.

Differences in the observed biomorphodynamics can be associated with different evolutionary paths of the active channel width (Figure $8 \mathrm{~A}$ ) and of vegetation biomass development (Figure 8B). The active channel narrows in the case of vegetated channels (lower set of curves in Figure 8A) and enlarges in environments where vegetation development is inhibited (upper set of curves in Figure $8 \mathrm{~A})$, and steadily fluctuates around a constant width value in the range 65-90 m and $130 \mathrm{~m}$, respectively. It is noteworthy that long periods of low stage (formative event every 2 years; case LF_G) or long event duration (LD_G) lead to a progressive decrease of the channel width without showing an oscillatory pattern, which corresponds to a much smoother floodplain surface in comparison with the conditions of the reference run. As could be expected, regular flow oscillations result in a regular temporal oscillation of active channel width and overall inner bank biomass, while non-periodic discharge patterns (LR_G, LR_B) produce more irregular fluctuations. Indeed, in the case of regular, periodic floods with constant magnitude, the discharge value that generates the inner bank (stable area) is never exceeded during the simulation. Conversely, when flood magnitude varies irregularly, the increase in the width (light blue thick line and line with circles) is related to 
the erosion of both the inner and outer bank, while it is only related to the erosion of the outer bank when flood magnitude is constant, as in the reference run.

Figure 7 also suggests that outer bank retreat is faster in the vegetated channels compared to the unvegetated ones. This result is quite interesting, especially considering that the coefficient $M$ used to model outer bank erosion (Equation 7) was kept constant in all simulations.

Figure $8 \mathrm{C}$ shows a decrease in the lateral bend migration rate during the first 30 years with a tendency towards a constant asymptotic value, and confirms that vegetated channels migrate laterally faster than unvegetated ones. Such a result allows the relative role of the 'bar push' and 'bank pull' phenomena to be discussed (see Discussion). Furthermore, despite differences in the evolution processes among the different tests, the average bed elevation seems to reach an almost constant value close to $-0.1 \mathrm{~m}$, regardless of the bio-hydrological conditions (Figure 8D).
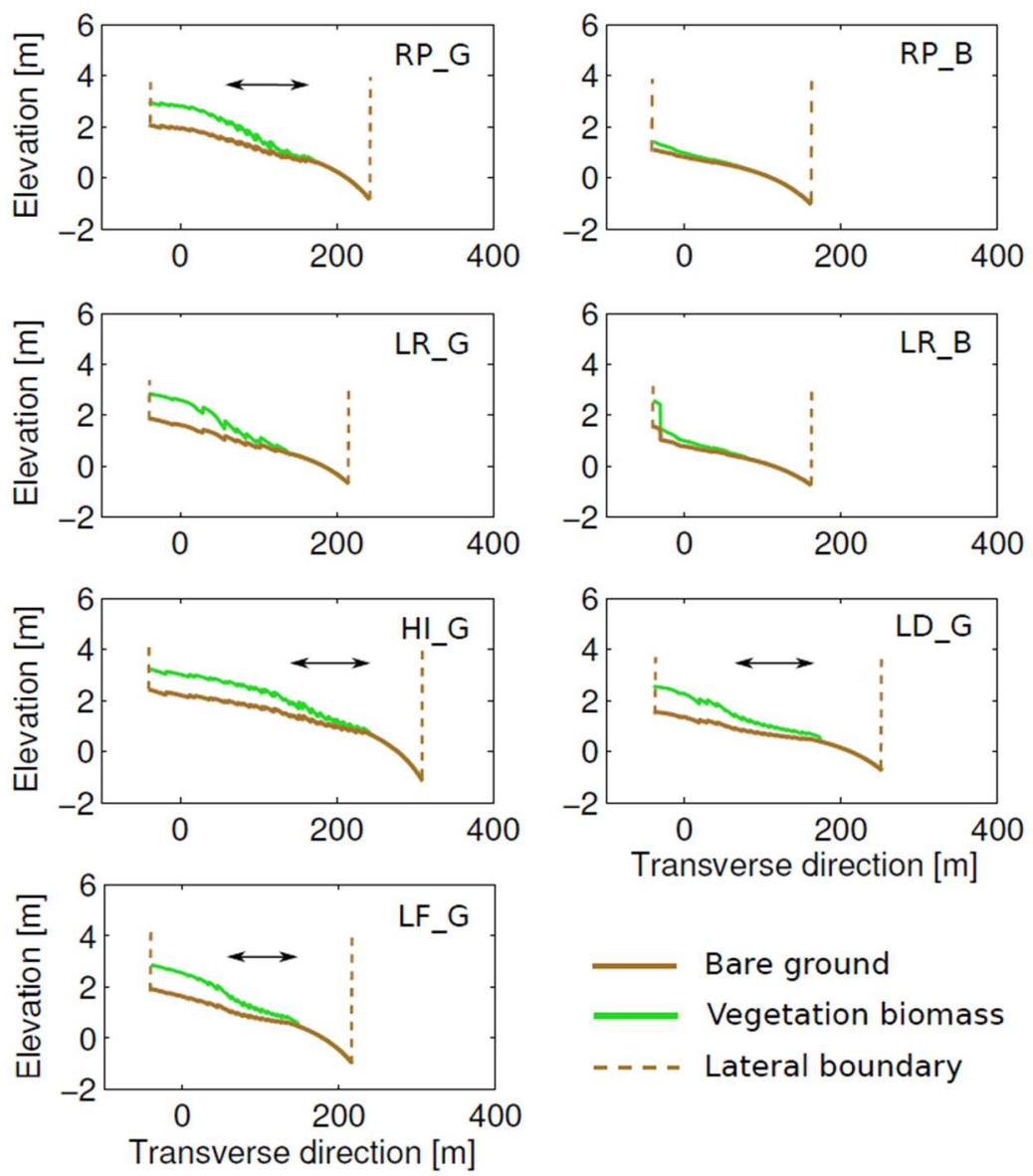

- - - - Lateral boundary

Figure 7 Temporal evolution of the channel cross-section (brown thick line) and biomass (green line) for the different hydro-biological scenarios listed in Table 1. For the sake of visualization, the biomass (green line) is conventionally represented in the same units of measurements as the ground topography. 

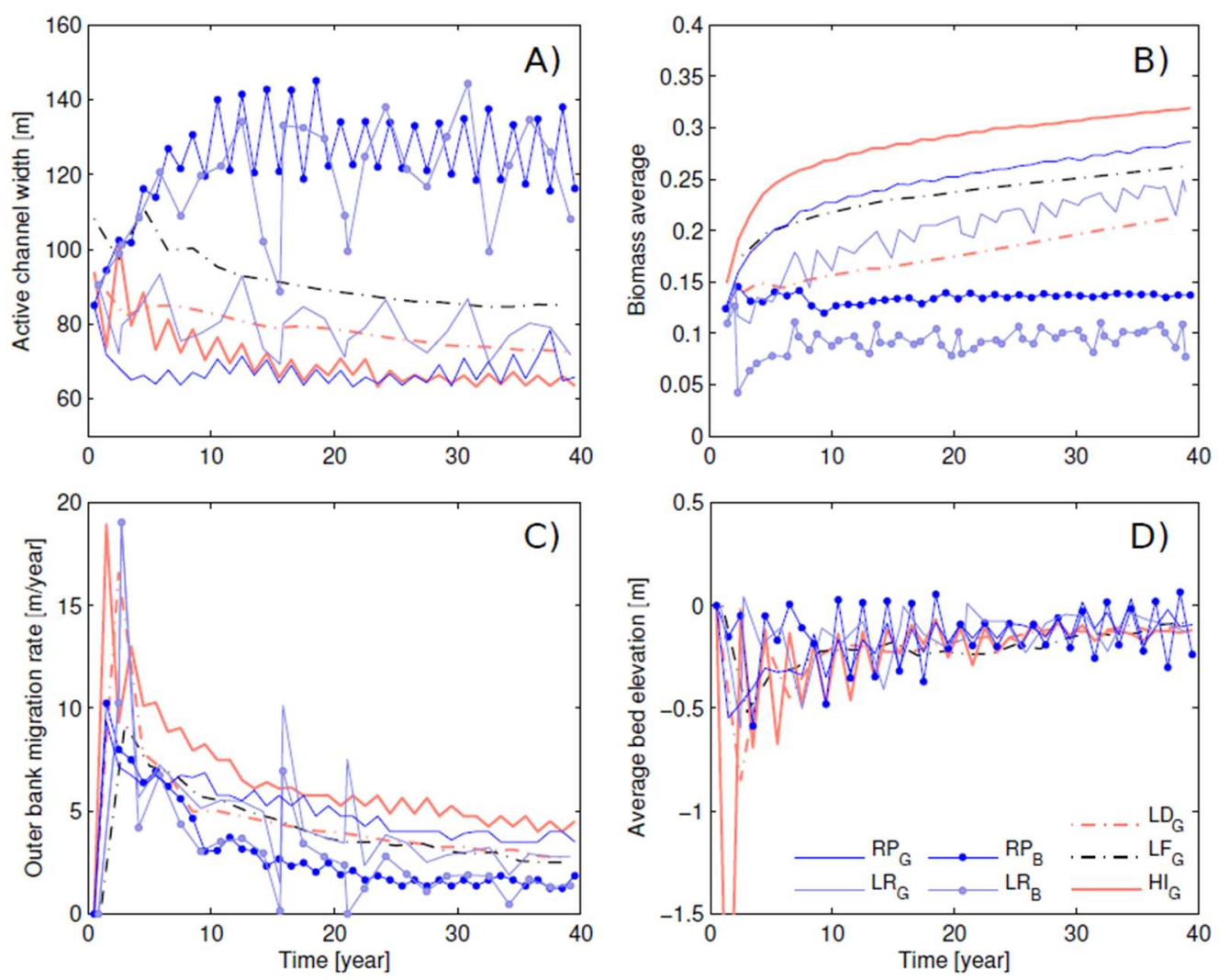

Figure 8 Temporal evolution of A) active channel width, B) average biomass, C) outer bank migration rates, and D) average bed elevation within the active channel, for the different cases investigated (see Table 1 for run ID). Curves that include markers refer to environments where vegetation growth is inhibited.

Comparison between the long-term simulation runs conducted by varying the initial width of the channel revealed that the initially imposed geometry does not affect the morphological equilibrium configuration of the system (see Figure 9). Results show the temporal variation of the active channel width over 120 years (thin lines) and the related evolutionary trend (thick lines) computed as a moving average using a 10-year window, both for the over-narrow and over-wide initial channel. During the early stages of evolution the over-wide vegetated channel (Figure 9A) narrows, while the width in the over-narrow channel first increases and then decreases until reaching a similar behaviour to the other case (Figure 9A). However, when vegetation growth is hampered, the river channel initially enlarges, with the initially narrower channel increasing its width much faster than the other in the first 20 years, to finally reach the same asymptotic configuration (see Figure 9B). It is also interesting to notice that the oscillating pattern of the active channel width is less regular in the case of the vegetated channel (Figure 9A).

In both environmental configurations, the channels adjust their width to reach a quasiequilibrium value, regardless of the initial width. However, each scenario presents different equilibrium widths: approximately $70 \mathrm{~m}$ for the vegetated river (Figure 9A) and $122 \mathrm{~m}$ for the case in which environment conditions prevent plant growth (Figure 9B). Such differences between the two cases provide evidence of the fundamental role played by riparian vegetation in river morphological evolution. Interestingly, Figure 9A shows that the final channel width selected by the interactions between riparian vegetation, sediments and river flow, falls in the range of possible equilibrium widths (solid and dashed line in Figure 9) estimated by applying the quasi-universal empirical regime formula proposed by Parker (2007). 

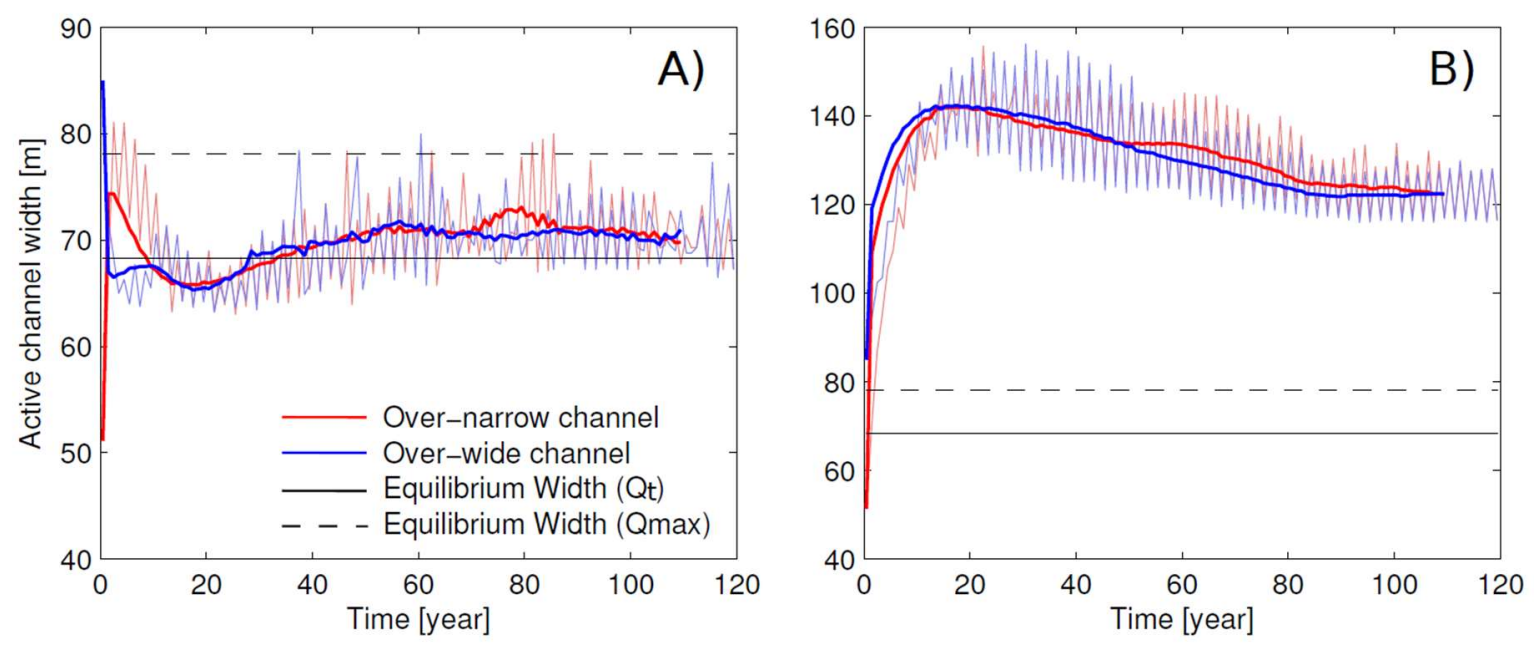

Figure 9 Temporal variation of active channel width for the cases of an initial over-narrow (red line) and overwide channel (blue line), for a A) vegetated (OW_G and ON_G in Table 1 ) and B) unvegetated channel (OW_B and ON_B in Table 1). The black horizontal lines represent the equilibrium width associated with the threshold discharge $Q_{t}$ (solid line) and the maximum discharge value $Q_{\max }$ (dashed line), estimated through the quasi-equilibrium relationship proposed by Parker (2007).

\subsection{Illustrative applications to real configurations}

The model was also applied to a bend of the lower Tagliamento River, see Figure 5). Figure 10 shows the cross-section resulting after 9 years of bio-morphological interactions (solid thick line) together with the initial cross-section (dashed line) and the transversal profile surveyed in 2014 (solid line). The cross-section simulated at the end of the period can be subdivided into a portion of the inner bank (from 20 to $100 \mathrm{~m}$ ) characterized by small oscillations of the ground surface, a zone (from 100 to $220 \mathrm{~m}$ ) where bed elevation decreases rapidly forming steps, and a smooth active channel (from 220 to $330 \mathrm{~m}$ ). The lateral migration is well reproduced, while the transect topography is only roughly simulated, as the model does not capture the observed topographic irregularities, especially when approaching the channel region from the advancing floodplain region.

A similar test was repeated to explore the effect of eroding bank protection structures on the biomorphodynamic evolution of the system. This was achieved by preventing outer bank erosion after 5 years of evolution, as it actually happened in a nearby downstream bend of the same river. Figure 11 shows the temporal evolution of the river transect (dashed lines) together with the final topography (thick solid line) and the final section of the previous simulation, where banks were free to migrate. The comparison between the predicted cross-section and the evolving section with freely erodible banks suggests that outer bank protection may produce a net separation between the advancing floodplain region and the active channel, which is more incised than in the free-bank case. The sharp separation between the two regions is characterized by a pronounced lateral bed slope around $110 \mathrm{~m}$ in Figure 11. Moreover, the system reacts to the immobilization of the outer bank by creating a flatter floodplain region and a steeper channel region compared to the free banks case. 


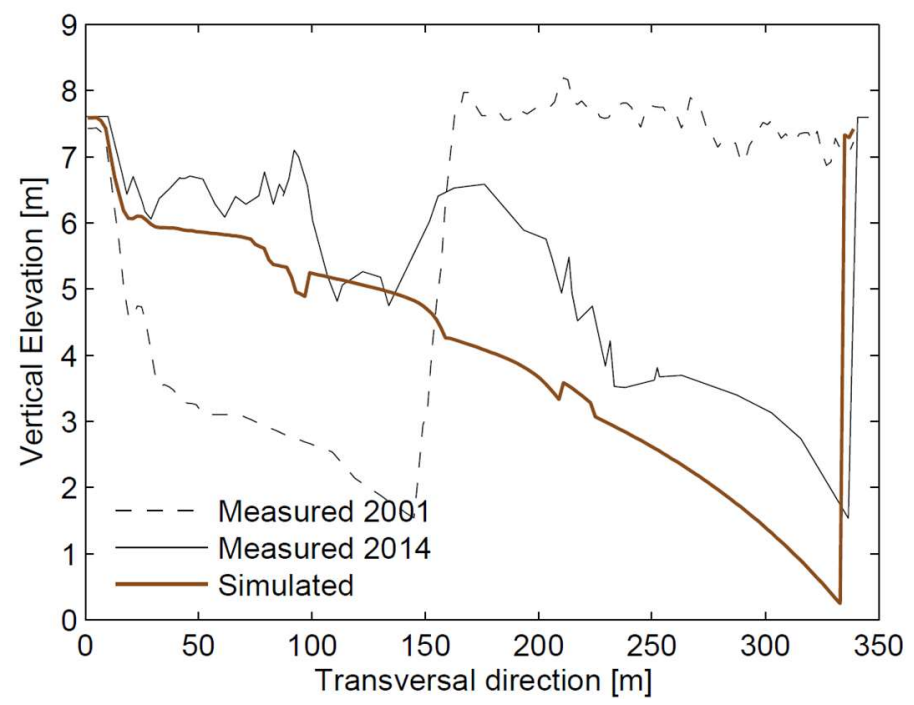

Figure 10 Channel cross section adjustments obtained by applying the proposed model (brown thick line) to a real cross-section of the Tagliamento River (Italy), extracted from a 2001 LiDAR survey (dashed black line). The result is compared with the cross-section surveyed in 2014 (solid black line).

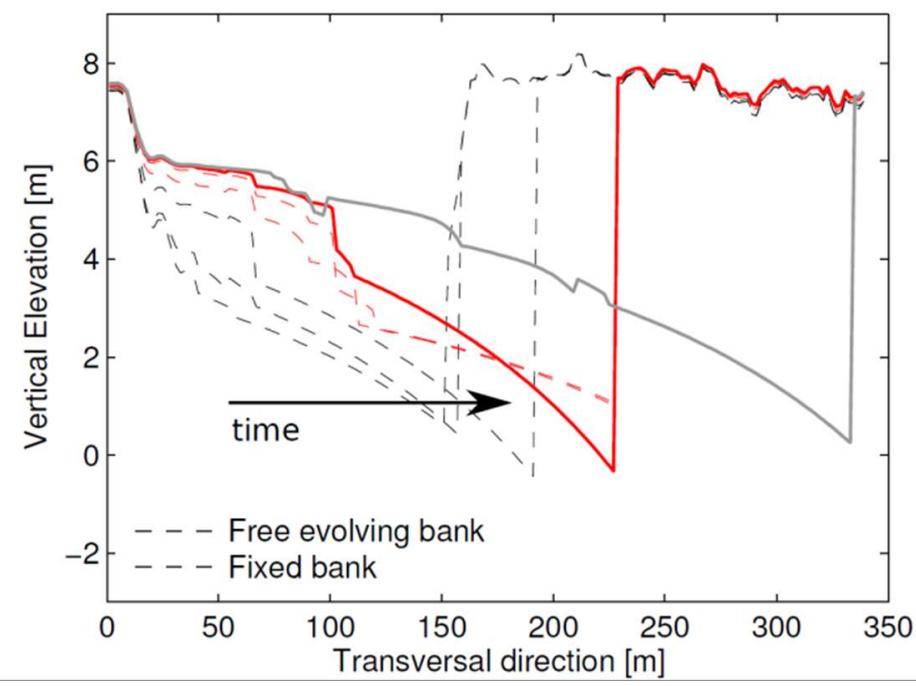

Figure 11 Temporal evolution (dashed lines) of a real cross-section of the Tagliamento River (Italy), modelled for 9 years, where the position of the external bank was fixed after 5 years. Black dashed lines refer to the simulated transect prior to bank stabilization and red dashed lines to the steps after it. The final result (red thick line) is compared with the cross-section obtained in the simulation presented in Figure 10 (solid black line) where the erodibility of the outer bank was kept constant.

\section{Discussion}

Results obtained through the simple model proposed in this paper show the potential of simulating bio-morphodynamic interactions in advancing meander bends by developing hybrid numericalanalytical models, as suggested by Seminara and Bolla Pittaluga (2012) for purely morphodynamic processes. This is consistent with findings from previous 'lumped' models that have been shown to allow effective investigation for the underlying physics of several hydromorphological processes (Cantelli et al., 2006; Camporeale and Ridolfi, 2006; Tealdi et al., 2011a; Tealdi et al., 2011b). The results of the analysis are here discussed highlighting (i) the insight allowed by the model into the role of the interacting biophysical processes, namely in relation to the bar push - bank pull 
mechanisms; (ii) the topographic and vegetation patterns produced by those interactions; (iii) the role of the external controls on such processes and patterns; and (iv) the model limitations.

\section{Vegetation and topography patterns}

The model simulations allow insight into two mechanisms that, when acting in tandem, produce lateral and vertical accretion and generate complex landforms within the inner bank area. The resulting transverse oscillation of the ground surface at the inner bank is due to the temporal variability in river discharge that determines whether the inner bank extends or retreats. This variation leads to a new configuration of the point bar that modifies the inner bank profile. Further modifications result from vertical accretion induced by the interaction between vegetation and the flow field during over-bank flows. Field observations have suggested that the presence of riparian shrubs, trees or wood, modify scour and deposition patterns and initiate complex landforms that evolve into a ridge and swale topography (e.g. Nakayama et al., 2002; Gurnell et al., 2012). Despite the simplistic assumption of a continuous transverse vegetation biomass distribution that does not allow the observed discrete variability to be encapsulated, the model tested in this paper has been able to reproduce small-scale oscillations of the ground surface within the inner bank. Figure 12A shows that these morphological features are qualitatively similar to the structure illustrated in Figure 12B. The modelling results show that the vegetation-related vertical accretion mechanism occurring within the inner bank area generates a smooth region far from the river channel edge that eventually corresponds to the natural floodplain elevation ( $\eta=2 \mathrm{~m}$ in Figure $6 \mathrm{~A}$ ).

The proposed method produces realistic river topography and riparian vegetation patterns that are qualitatively similar to those observed in the field (e.g. Rodnight et al., 2005; Rozo et al., 2012). On this basis, it can be argued to underpin the further development of topographic and vegetation structures in the advancing floodplain. The combined effect of these two accretion mechanisms leads to an inner bank displaying topographic oscillations at two different spatial scales. The smaller spatial scale is associated with ridge-swale oscillations and is tied with the flood event time scale, producing the corrugated topography of the advancing floodplain. A larger spatial scale, associated with the channel width, seems to characterize the inner bank patterns especially under a regular hydrological forcing (see Figure 7). Looking at the examples reported in the aerial images of Figure 1 , and on the basis of the qualitative correspondence of our results with the patterns reported in Figure 12, it can be hypothesized that the small-scale morphological structures, generated at the flood event time scale, tend to evolve into floodplain patterns with a lateral spacing of the order of the channel width. However the model is not able at present to properly describe the long-term evolution of scour-deposition sequences developing within the inner bank (close-up of Figure 12A), because equation (7) invariably implies faster filling of swales compared to ridges. This eventually results in the progressive flattening of the initially corrugated floodplain surface and vegetation biomass lateral distribution. 
A)

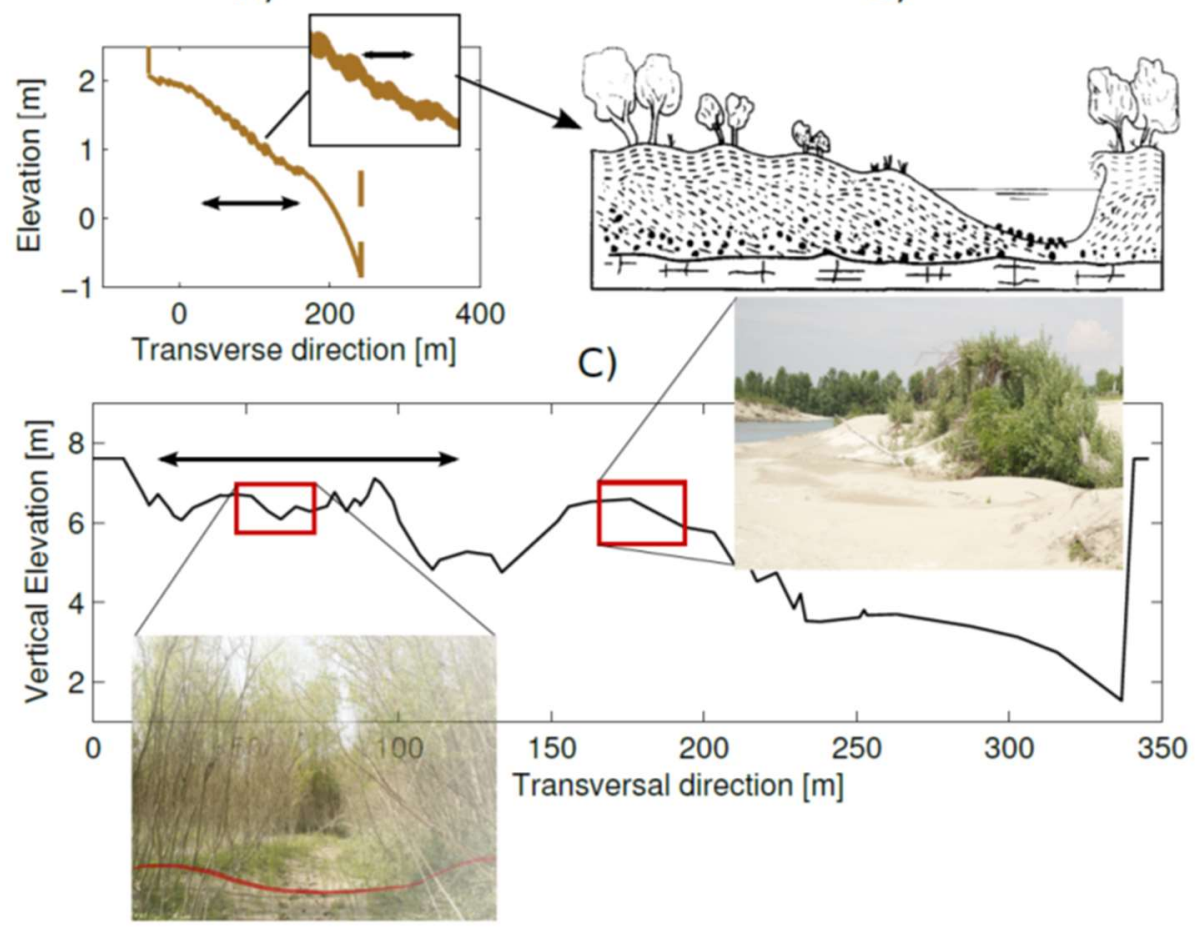

Figure 12 Composite image showing: A) an example of channel bed transversal profile obtained from the simulations; B) generalized model of lateral accretion in scrolled floodplains from Nanson and Crooke (1992); C) surveyed cross-section of the Tagliamento River (Italy) with two examples of the different vegetation environments and ground patterns that characterize the inner bank.

\section{Hydrological and environmental controls on bend biomorphodynamics}

Analysis of the temporal variation of the channel width shows that the presence of vegetation within the inner bank prevents the occurrence of a 'runaway' widening mechanism, whereby the eroding bank retreats much faster than the opposite bank advancing (sensu Eke et al., 2014). This result agrees with laboratory experiments in which the development of a stable meandering form have required the use of cohesive material (van Dijk et al., 2013) or living vegetation (e.g. alfalfa sprouts, Braudrick et al., 2009; Tal and Paola, 2010) to limit channel widening. It is also noteworthy that in all the modelled cases, the main controlling factor on the evolution of the channel width was due to accretion processes occurring at the inner bank rather than to the outer bank resistance to erosion, because the coefficient $M$ (equation 14) was kept constant in all simulation runs. Moreover, the simulated cross-sections of Figure 7 show that, in the presence of favourable environment conditions for vegetation growth, the bio-morphological interactions promote pattern irregularity into the advancing floodplain area. Conversely, when vegetation development is inhibited, the inner bank appears less expanded with a smooth ground surface (see panels RP_B and LR_B in Figure 7).

Furthermore, results indicate that the river width temporal evolution does not only depend on the presence of vegetation, but also on the nature of the hydrological disturbance. This is evidenced by the cases of a vegetated floodplain affected by periodic floods of same magnitude (RP_G, HI_G, LF_G and LD_G). In these cases, the erosion of the outer bank during the flood event increases the channel width, which in turn decreases the river water stage. As a consequence vegetation colonizes the newly exposed sediments and stabilises the ground. Therefore, in the absence of a higher 
discharge, the inner bank keeps advancing and reducing the channel width until a new flood producing channel widening through erosion of the outer bank. This process is recognizable in the oscillating pattern of Figure 8A and agrees with the field observations of Nanson (1981) in which the outer bank moves and the opposite bank is documented to periodically catch up. Thus, the channel enlarges via outer bank 'pull', which further induces narrowing processes through bar 'push', as suggested by Eke et al. (2014) who applied a more simplified closure relation to describe inner bank advance.

The simulations characterized by varying flood magnitudes (LR_G and LR_B) show a less regular pattern of width oscillations (see Figure $8 \mathrm{~A}$ ), suggesting the hydrologic control on width variability. In these cases, some flood events may determine erosion also of the inner bank, by leading to a portion of the inner bank becoming morphologically active. Such behaviour is related to sediment mobility and is influenced by the soil reinforcement provided by vegetation. Therefore, the higher the biomass value, the higher the magnitude of the flood event required to activate erosion processes at the inner bank. This latter result agrees with the concept of the 'fluvial biogeomorphic cycle' proposed by Corenblit et al. (2007) and supported by field measurements (Corenblit et al., 2009b) and so further supports the ability of the developed model to reproduce, at least qualitatively, observed biophysical dynamics.

\section{Bar push, bank pull and temporal width variability}

The developed model has provided a first attempt to quantify the effect of a vegetation-related bar push mechanism on meander bend evolution. The analysis of the migration rates computed at the several stages of evolution for the different cases reveals that unvegetated channels advance less, and more slowly, than vegetated channels. This difference can be attributed to the impact of vegetation colonisation and interaction with fluvial processes on the inner bank. This is illustrated in Figure $8 \mathrm{C}$ and can be interpreted as follows: the stronger the encroachment of vegetation within the point bar, the greater the initiation of vegetation-related, sediment aggrading landforms. As a consequence, the stronger the migration of the floodplain margin, the greater the rate at which the river bend shifts laterally. Another mechanism that could promote the erosion of the outer bank, and therefore affect the lateral migration rate of the meander bend, is the failure of the bank due to the additional load caused by the presence of vegetation. This phenomenon deposits blocks of cohesive sediments at the bank toe (slump blocks), which temporarily exert a protective action from the erosion of the sediments (Parker et al., 2011). Although recognized relevant for the dynamics of the eroding bank, these processes were not explicitly accounted for in this analysis because of its main focus on the dynamics of the inner bank. Interestingly, long-term simulations under periodic floods suggest that the channel tends to an equilibrium active width without such a protective effect.

The equilibrium width is related to the bio-hydrological dynamics, but does not depend on the initial assigned width (see Figure 9). This behaviour can be explained by referring to the 'bank pull' process. Such a mechanism indeed promotes channel widening through bank erosion, determining the decrease of the local water depth and, therefore, of the longitudinal shear stress experienced at the toe of the external bank. As a result, the cutting bank retreats less and less, asymptotically limiting channel widening and progressively damping the lateral migration process. The vegetated channel shows a similar behaviour (Figure 9A), although here the inner bank advance sustains the morphological evolution of the channel by constantly 'pushing out' the external bank. Indeed, in vegetated river corridors the newly constituted inner bank area at lower elevation can be flooded and this contributes to diminishing the local water depth in the active channel. However, because of the presence of vegetation and associated landforms within the inner bank, which limit the 
channel active width, the effect turns out to be less intense. This leads to higher equilibrium values of shear stress that reflect higher migration rates (Figure $8 \mathrm{C}$ ).

Application of the model to a real case (Tagliamento River, Italy) showed the potential of the model to predict overall inner bank accretion similar to that observed in the field (i.e. Figure 10), with the predicted cross-section presenting different zones distinguished by different topographical features. However, the simulated oscillatory topographical structures that characterize the simulated cross-section appear less pronounced than in the real cross-section (Figure 10), and the complex morphological structures in the field cannot be exactly reproduced by the proposed model. Indeed, the simplistic hypotheses introduced in the model do not allow the complex variability to be captured that is related to the three-dimensional flow field generated by the interaction between flow, vegetation encroachment or deposited wood within the point bar deposit (e.g. Nakayama et al., 2002 and Figure 12C). It should be noted that the aim of such an application is not to predict the detailed evolution in a specific real case, but rather to describe the mutual interaction among relevant biophysical processes within a realistic context. Finally, results of the test that simulate the presence of a bank protection structure at the outer bank suggest that the active channel may become disconnected from its floodplain as a consequence. The lateral erosion of the outer bank is inhibited, therefore morphological changes occur only through vertical variations. As a result the inner bank presents a more elevated, flat and horizontal bed profile with respect to the cross-section obtained running the same simulation without limiting the lateral migration of the channel bend (Figure 11).

\section{Model limitations}

Overall, results obtained provide evidence of the model's ability to capture the bio-physical processes that probably underline the overall dynamics and the typical topographical patterns that characterize the advancing floodplain in natural river meanders. However, a detailed reproduction of floodplain patterns like the ones depicted in Figure 1 still requires several model improvements. In particular, the longitudinal (streamwise) dimension needs to be included in the model in order to overcome the hypothesis of constant curvature that limits the analysis to the river cross-section. This hypothesis was introduced to keep the highest level of simplicity within this first attempt to describe the mutual feedbacks among vegetation, river flow and morphology in a migrating meander bend. A less simplistic model for the dynamics of the outer bank is also required in order to include the temporal variation of bank sediments erodibility (e.g. increased resistance to the erosion due to the presence of slump blocks or the development of plant root systems). Moreover, the closure for the sedimentation processes, introduced to model the vegetation-related morphological structures within the floodplain area, progressively smooths out the small oscillations of the ground surface observed in the simulation outcomes. Thus, the long-term evolution of the width-scale oscillations that could be interpreted as initiators of scroll bars, cannot be properly explored.

\section{Conclusions}

The present work, by separately modelling the evolution of the inner and the outer banks of a meander bend, and by explicitly accounting for the active role of riparian vegetation in the advancing bank, constitutes a novel step in understanding biophysical interactions likely to control fluvial processes of meander evolution. The model is a first, biophysically-based attempt to overcome the simplifying hypothesis of constant channel width on which meander migration 
models have been traditionally based. In particular, it allows for further understanding of the role of bar 'push' and 'pull' mechanisms through which the meander bend evolves. Differently from the closure for bank erosion and deposition proposed by Eke et al. (2014), which is based on the framework for self-evolving banks of Parker et al. (2011), here we relate the advance of the inner bank to the active role of riparian vegetation dynamics on the point bar by means of biophysicallybased relationships for vegetation biomass growth and decay.

The model also allows investigation of the incipient conditions for topographical and vegetational pattern development in the advancing floodplain, suggesting the development of a corrugated floodplain topography (short-scale oscillations) and also of longer topographic oscillations that scale with the channel width. Thanks to its relative simplicity, the model also allows investigation of the role played by different hydrograph properties (magnitude, frequency, duration and regularity of floods) on the processes of bar push, width oscillations, floodplain pattern development, and related temporal scales.

Further research shall include improvements in the meander sub-model (i.e. spatially varying curvature, flow unsteadiness, spatial width variations) and in the vegetation sub-model (i.e. accounting for variations in sediment moisture due to temporal fluctuations of the water table). Moreover, systematic and quantitative field data on evolving meander bends in vegetated floodplains with little anthropogenic effect are needed, on the line of a multidisciplinary approach that is essential in biogeomorphic studies (e.g. Camporeale et al., 2013)

\section{Acknowledgments}

The authors acknowledge Alessandro Cantelli and two anonymous reviewers whose relevant comments and suggestions contributed to improving the quality of the paper.

This work has been partially carried out within the SMART Joint Doctorate (Science for the MAnagement of Rivers and their Tidal systems) supported by the Erasmus Mundus programme of the European Union, and supported by the project ETSCH2000 funded by the Autonomous Province of Bolzano, Italy.

\section{Bibliography}

Allmendinger, N.E., Pizzuto, J.E., Potter, N., Johnson, T.E., \& Hession, W.C., 2005. The influence of riparian vegetation on stream width, eastern Pennsylvania, USA. Geological Society of America Bulletin, 117, 229243.

Bertoldi, W., A. M. Gurnell, N. Surian, K. Tockner, L. Zanoni, L. Ziliani, and G. Zolezzi (2009), Understanding reference processes: Linkages between river flows, sediment dynamics and vegetated landforms along the Tagliamento River, Italy, River Res. Appl., 25, 501-516.

Bertoldi, W., Gurnell, A. M., \& Drake, N. A., 2011b. The topographic signature of vegetation development along a braided river: Results of a combined analysis of airborne lidar, color air photographs, and ground measurements. Water Resour. Res., 47, W06525, doi:10.1029/2010WR010319.

Bertoldi, W., A. Siviglia, S. Tettamanti, M. Toffolon, D. Vetsch, and S. Francalanci., 2014. Modeling vegetation controls on fluvial morphological trajectories. Geophysical Research Letters, 41(20), 7167-7175, doi.org/10.1002/2014GL061666. 
Bolla Pittaluga, M., G. Nobile, and G. Seminara, 2009. A nonlinear model for river meandering, Water Resour. Res., 45, 04432, doi:10.1029/2008WR007298.

Bolla Pittaluga, M., \& Seminara, G., 2011. Nonlinearity and unsteadiness in river meandering: a review of progress in theory and modelling. Earth Surf. Process. Landforms, 36, 20-38, DOI: 10.1002/esp.2089.

Braudrick, C., Dietrich, W., Leverich, G., \& Sklar, L., 2009. Experimental evidence for the conditions necessary to sustain meandering in coarse-bedded rivers. Proceedings of the National Academy of Sciences of the United States of America, 106, 16936-16941.

Camporeale, C., P. Perona, A. Porporato, and L. Ridolfi , 2005, Hierarchy of models for meandering rivers and related morphodynamic processes, Rev. Geophys., 45, RG1001, doi:10.1029/2005RG000185.

Camporeale, C., Perucca, E., Ridolfi, L. \& Gurnell, A., 2013. Modeling th einteractions between river morphodynamics and riparian vegetation. Rev. Geophys., 51, 379-414, doi:10.1002/rog.20014..

Camporeale, C., \& Ridolfi, L., 2006. Riparian vegetation distribution induced by river flow variability: A stochastic approach. Water Resources Research, 42, W10415, doi:10.1029/2006WR004933.

Camporeale, C., \& Ridolfi, L., 2010. Interplay among river meandering, discharge stochasticity and riparian vegetation. Journal of Hydrology, 382, 138-144.

Cantelli, A., M. Wong, G. Parker, and C. Paola (2007), Numerical model linking bed and bank evolution of incisional channel created by dam removal, Water Resour. Res., 43, W07436, doi:10.1029/2006WR005621.

Constantine, C. R., Dunne, T., \& Hanson, G. J., 2009. Examining the physical meaning of the bank erosion coefficient used in meander migration modeling. Geomorphology, 106(3-4), 242-252, doi.org/10.1016/j.geomorph.2008.11.002.

Corenblit, D., Steiger, J., Gurnell, A. M., \& Naiman, R., 2009a. Plants intertwine fluvial landform dynamics with ecological succession and natural selection: a niche construction perspective for riparian systems. Global Ecology and Biogeography, 18(4), 507-520.

Corenblit, D., Steiger, J., Gurnell, A. M., Tabacchi, E., \& Roques, L., 2009b. Control of sediment dynamics by vegetation as a key ecological function within fluvial corridors. Earth Surfaces Processes and Landforms, 34(13), 1790-1810.

Corenblit, D., Tabacchi, E., Steiger, J., \& Gurnell, A. M., 2007. Reciprocal interactions and adjustments between fluvial landforms and vegetation dynamics in river corridors: a review of complementary approaches. Earth Science Reviews, 84, 56-86, DOI: 10.1016/j.catena.2007.11.002.

Crosato, A., 2007, Effects of smoothing and regridding in numerical meander migration models, Water Resour. Res., 43, W01401, doi:10.1029/2006WR005087.Crouzy, B., \& Perona, P., 2012. Biomass selection by floods and related timescales. Part 2: Stochastic modeling. Advances in Water Resources, 39, 97-105.

Darby, S. E., A. M. Alabyan, and M. J. Van de Wiel, 2002. Numerical simulation of bank erosion and channel migration in meandering rivers, Water Resour. Res., 38(9), 1163, doi:10.1029/2001WR000602.

Darby, S. E., Rinaldi, M., \& Dapporto, S., 2007. Coupled simulations of fluvial erosion and mass wasting for cohesive river banks. J. Geophys. Res., 112, F03022, doi:10.1029/2006JF000722.

Dean, R. B., 1974, Reynolds number dependence on skin friction in twodimensional rectangular duct flow and a discussion on the law of the Wake, Aero Rep. 74-11, Imperial Coll. London, London

Eke, E., Gary, P., \& Yasuyuki, S., 2014. Numerical modeling of erosional and depositional bank processes in migrating river bends with self-formed width: morphodynamics of bar push and bank pull. J. Geophys. Res., 119(7), 1455-1483. 
Engelund, F., 1964. Flow resistance and hydraulic radius. Basic Research Progress Rep., 6, 3-4, ISVA, Technical Univ. of Denmarck.

Frascati, A., and S. Lanzoni , 2009, Morphodynamic regime and longtermevolution of meandering rivers, J. Geophys. Res., 114, F02002, doi:10.1029/2008JF001101.

Grenfell, M., Aalto, R., \& Nicholas, A., 2011. Chute channel dynamics in large, sand-bed meandering rivers. Earth Surf. Process. Landforms, 37, 315-331, DOI:10.1002/esp.2257.

Güneralp, I., \& Rhoads, B., 2011. Influence of floodplain erosional heterogeneity on planform complexity of meandering rivers. Geophys. Res. Lett., 38, doi:10.1029/2011GL048134(L14401).

Gurnell, A., 2014. Plants as river system engineers. Earth Surface Processes and Landforms, 39, 4-25.

Gurnell, A., 2016. Trees, wood and river morphodynamics: results from 15 years research on the Tagliamento river, Italy. In: D. Gilvear, M. Greenwood, M. Thoms \& P. Wood (eds.), River Science: Research and Applications for the 21st Century. John Wiley and Sons, in press.

Gurnell, A. M., \& Petts, G. E., 2006. Trees as riparian engineers: the Tagliamento River, Italy. Earth Surface Processes and Landforms, 31, 1558-1574, Doi 10.1002/esp.1342 .

Gurnell, A.M., Petts, G.E., Hannah, D.M., Smith, B.P.G., Edwards, P.J, Kollmann, J., Ward, J.V., \& Tockner, K., 2001. Riparian vegetation and island formation along the gravel-bed fiume Tagliamento, Italy. Earth Surf. Process. Landforms, 26, 31-62.

Gurnell, A., Blackall, T., \& Petts, G., 2008a. Characteristics of freshly-deposited sand and finer sediments along an island-braided, gravel bed river: the roles of water, wind and trees. Geomorphology, Volume 99, pp. 254-269, DOI: 10.1016/j.geomorph.2007.11.009.

Gurnell, A., Thompson, K., Goodson, J., \& Moggridge, H., 2008b. Propagule deposition along river margins: linking hydrology and ecology. Journal of Ecology, 96, 553-565, DOI: 10.1111/j.1365-2745.2008.01358.x.

Gurnell, A. M., Bertoldi, W., \& Corenblit, D., 2012. Changing river channels: The roles of hydrological processes, plants and pioneer fluvial landforms in humid temperate, mixed load, gravel bed rivers. EarthScience Reviews, 111, 129-141.

Hickin, E. J., 1974. The development of meanders in natural river-channels. American Journal of Science, 274, 414-442.

Hickin, E., \& Nanson, G., 1975. The Character of Channel Migration on the Beatton River, Northeast British Columbia, Canada. Geological Society of America Bulletin, 86(4), 487-494.

Hooke, J., 2007. Spatial variability, mechanisms and propagation of change in an active meandering river. Geomorphology, 84, 277-296.

Hooke, J., 2008. Temporal variations in fluvial processes on an active meandering river over a 20-year period. Geomorphology, 100, 3-13.

Howard, A., 1992, Modelling channel evolution and floodplain morphology, in Floodplain Processes, edited by M. G. Anderson, D. E. Walling, and P. D. Bates, 15-62, John Wiley, New York.

Ikeda, S., Parker, G., \& Sawai, K., 1981. Bend theory of river meanders. Part 1 - Linear development. J. Fluid Mech., 112, 363-377.

Johannesson, H., \& Parker, G., 1989. Linear theory of river meanders. In: River Meandering. s.l.:Washington DC, Water Res. Monograph 12, Amer. Geoph. Union., 181-214. 
Johnson, W. C., M. D. Dixon, R. Simons, S. Jenson, and K. Larson, 1995. Mapping the response of riparian vegetation to possible flow reductions in the Snake River, Idaho, Geomorphology, 13, $159-173$.

Kleinhans, M. G., \& van den Berg, J. H., 2011. River channel and bar patterns explained and predicted by an empirical and a physics-based method. Earth Surface Processes And Landforms, 36, 721-738, doi:10.1002/esp.2090.

Lauer, J., \& Parker, G., 2008. Net local removal of floodplain sediment by river meander migration. Geomorphology, 96, 123-149, doi: 10.1016/j.geomorph.2007.08.003.

Leopold, L., \& Wolman, G., 1960. River meanders. Bulletin of the Geological Society of America, 71.

Lotter, G. K., 1933. Considerations on hydraulic design of channels with different roughness of walls. Izvestiia Vsesoiuznago Nuchno-Issledovatel'skogo Instituta Gildrotekhniki Leningrad, 9, 238-241 (in Russian).

Luchi, R., Zolezzi, G., \& Tubino, M., 2011. Bend theory of river meanders with spatial width variations. J. Fluid Mech, 681, 311-339, doi:10.1017/jfm.2011.200.

Mahoney, J. M., \& Rood, S. B., 1998. Streamflow requirements for cottonwood seedling recruitment - an integrative model. Wetlands, 18(4), pp. 634-645.

Marani, M., Da Lio, C., \& D'Alpaos, A., 2013. Vegetation engineers marsh morphology through multiple competing stable states. Proc. Natl. Acad. Sci., 110(9), 3259-3263.

McKenney, R., Jacobson, R. B., \& Wertheimer, R. C., 1995. Woody vegetation and channel morphogenesis in low-gradient, gravel-bed streams in the Ozark Plateaus. Missouri and Arkansas. Geomorphology, 13, 175198.

Meyer-Peter, E., \& Muller, R., 1948. Formulas for bed load transport. s.l., Proceedings of 2nd Meeting IAHSR, Stockholm, Sweden.

Nakayama, K., Fielding, C. R., \& Alexander, J., 2002. Variations in character and preservation potential of vegetation-induced obstacle marks in the variable discharge Burdekin River of north Queensland, Australia. Sedimentary Geology, 149, 199-218.

Nanson, G. C., 1980. Point bar and floodplain formation of the meandering Beatton River, northeastern British Columbia, Canada. Sedimentology, 27, 3-29.

Nanson, G. C., 1981. New evidence of scroll-bar formation on the Beatton River. Sedimentology, 28, 889891.

Nanson, G., \& Croke, J., 1992. A genetic classification of floodplains. Geomorphology, 4(6), 459-486.

Nanson, G., \& Hickin, E., 1983. Channel migration and incision on the Beatton River. Journal of Hydraulic Engineering, 109, 327-337.

O'Neal, M. A., \& Pizzuto, J. E., 2011. The rates and spatial patterns of annual riverbank erosion revealed through terrestrial laser-scanner surveys of the South River, Virginia. Earth Surf. Process. Landforms, 36, 695-701.

Page, K., \& Nanson, G., 1982. Concave-bank benches and associated floodplain formation. Earth Surface Processes and Landforms, 7, 529-543.

Parker, G., Y. Shimizu, G. V. Wilkerson, E. C. Eke, J. D. Abad, J. W. Lauer, C. Paola, W. E. Dietrich, \& V. R. Voller, 2011. A new framework for modeling the migration of meandering rivers. Earth Surface Processes and Landforms, 36, 70-86, doi:10.1002/esp.2113. 
Parker, G., P. R. Wilcock, C. Paola, W. E. Dietrich, and J. Pitlick , 2007. Physical basis for quasi-universal relations describing bankfull hydraulic geometry of single-thread gravel bed rivers. J. Geophys. Res., 112, F04005, doi:10.1029/2006JF000549.

Perona, P., Molnar, P., Crouzy, B., Perucca, E., Jiang, Z., Mclelland, S., Wuthrich, D., Edmaier, K., Francis, R., Camporeale, C., \& Gurnell, A., 2012. Biomass selection by floods and related timescales: Part 1.

Experimental observations. Advances in Water Resources, 39, 85-96.

Perucca, E., Camporeale, C., \& Ridolfi, L., 2006. Influence of river meandering dynamics on riparian vegetation pattern formation. Journal of Geophysical Research, 111, G01001, doi:10.1029/2005JG000073.

Perucca, E., Camporeale, C., \& Ridolfi, L., 2007. Significance of the riparian vegetation dynamics on meandering river morphodynamics. Water Resources Research, 43, W03430, doi:10.1029/2006WR005234.

Robertson, K. M., 2006. Distributions of tree species along point bars of 10 rivers in the south-eastern US Coastal Plain. Journal of Biogeography, 33, 121-132.

Robertson, K. M., \& Augspurger, C. K., 1999. Geomorphic processes and spatial patterns of primary forest succession on the Bogue Chitto River, USA. Journal of Ecology, 87, 1052-1063.

Rodnight, H., Duller, G., Tooth, S., \& Wintle, A., 2005. Optical dating of a scroll-bar sequence on the Klip River, South Africa, to derive the lateral migration rate of a meander bend. The Holocene, 15, 802-811.

Rozo, M. G., Nogueira, A. C., \& Truckenbrodt, W., 2012. The anastomosing pattern and the extensively distributed scroll bars in the middle Amazon River. Earth Surf. Process. Landforms, 37, 1471-1488, DOI: 10.1002/esp.3249.

Seminara, G., 2006. Meanders. Paper invited for the 50th Anniversary issue of the J. Fluid. Mech., 554, 271297.

Seminara, G., \& Bolla Pittaluga, M., 2012. Reductionist versus holistic approaches to the study of river meandering:An ideal dialogue. Geomorphology, 163-164, 110-117.

Seminara, G., \& Solari, L., 1998. Finite amplitude bed deformations in totally and partially transporting wide channel bends. Water Resources Research, 34(6), 1585-1594.

Tal, M., \& Paola, C., 2010. Effects of vegetation on channel morphodynamics: results and insights from laboratory experiments. Earth Surf. Process. Landforms, 35, 1014-1028.

Tealdi, S., Camporeale, C., \& Ridolfi, L., 2011a, Modelling the impact of river damming on riparian vegetation, Journal of Hydrology, 396, 302-312.

Tealdi, S., Camporeale, C., \& Ridolfi, L., 2011b, Long-term morphological river response to hydrological changes, Advances in Water Resources, 34, 1643-1655.

Tockner, K., Ward, J. V., Arscott, D. B., Edwards, P. J., Kollmann, J., Gurnell, A. M., Petts, G. E., and Maiolini, B., 2003. The tagliamento river: A model ecosystem of European importance. Aquat. Sci., 65:239-253.

van Dijk, W. M., van de Lageweg, W. I., \& Kleinhans, M. G., 2013. Formation of a cohesive floodplain in a dynamic experimental meandering river. Earth Surf. Process. Landforms, 38, 1550-1565.

Walling, D.E., \& He, Q., 1998. The spatial variability of overbank sedimentation on river floodplains. Geomorphology, 24, 209-223.

Zen, S., 2014, Bio-morphodynamics of evolving river meander bends from remote sensing, field observations and mathematical modelling, PhD Thesis. 
Zolezzi, G., and G. Seminara, 2001, Downstream and upstream influence in river meandering. part 1. General theory and application to overdeepening, J. Fluid Mech., 438, 183-211.

Zolezzi, G., Luchi, R., \& Tubino, M., 2009. Morphodynamic regime of gravel bed, single-thread meandering rivers. Journal of Geophysical Research- Earth Surface, 114, F01005, doi:10.1029/2007JF000968.

Zolezzi, G., Luchi, R., \& Tubino, M., 2012. Modeling morphodynamic processes in meandering rivers with spatial width variations. Rev. Geophys., 50, RG4005, doi:10.1029/2012RG000392. 